\title{
Neurogenesis in the Developing and Adult Brain-Similarities and Key Differences
}

\author{
Magdalena Götz ${ }^{1,2,3}$, Masato Nakafuku ${ }^{4,5}$, and David Petrik ${ }^{1,2}$ \\ ${ }^{1}$ Institute of Stem Cell Research, Helmholtz Center Munich, 85764 Neuherberg, Munich, Germany \\ ${ }^{2}$ Physiological Genomics, Biomedical Center, Ludwig-Maximilians-University, 80336 Munich, Germany \\ ${ }^{3}$ Synergy, Munich Cluster for Systems Neurology, 81377 Munich, Germany \\ ${ }^{4}$ Cincinnati Children's Hospital Medical Center, Cincinnati, Ohio 45140 \\ ${ }^{5}$ Departments of Pediatrics and Neurosurgery, University of Cincinnati College of Medicine, Cincinnati, \\ Ohio 45267 \\ Correspondence: magdalena.goetz@helmholtz-muenchen.de; masato.nakafuku@cchmc.org
}

\begin{abstract}
Adult neurogenesis in the mammalian brain is often viewed as a continuation of neurogenesis at earlier, developmental stages. Here, we will critically review the extent to which this is the case highlighting similarities as well as key differences. Although many transcriptional regulators are shared in neurogenesis at embryonic and adult stages, recent findings on the molecular mechanisms by which these neuronal fate determinants control fate acquisition and maintenance have revealed profound differences between development and adulthood. Importantly, adult neurogenesis occurs in a gliogenic environment, hence requiring adult-specific additional and unique mechanisms of neuronal fate specification and maintenance. Thus, a better understanding of the molecular logic for continuous adult neurogenesis provides important clues to develop strategies to manipulate endogenous stem cells for the purpose of repair.
\end{abstract}

Tising ypically, neurogenesis in the adult mammalian brain is viewed as continuation of earlier processes from development (Kriegstein and Alvarez-Buylla 2009). This view has been corroborated by the similarity of neural stem cells (NSCs) during development and in adulthood that are in both cases radial glial cells (Götz and Huttner 2005; Kriegstein and Alvarez-Buylla 2009; Taverna et al. 2014). However, despite the morphological similarities between embryonic and adult radial glia, there are also profound differences, for example, in their genome-wide gene expression, as well as their pro- liferation and fate. Notably, adult NSCs resemble more bona fide glial cells, such as mature astrocytes or ependymal cells from the adult brain, whereas embryonic NSCs, the radial glial cells, resemble more adult neuroblasts (NBs) and transient amplifying progenitors (TAPs) in the same comparison (Beckervordersandforth et al. 2010; Götz et al. 2015). On the other hand, recent studies have revealed that neurogenic transcription factor $(\mathrm{TF})$ regulators used in embryonic and adult neurogenesis are very similar, comprising the homeodomain TFs Pax6, Gsx2, and Dlx (Hack et al. 2005; Kohwi

Editors: Fred H. Gage, Gerd Kempermann, and Hongjun Song

Additional Perspectives on Neurogenesis available at www.cshperspectives.org

Copyright (C) 2016 Cold Spring Harbor Laboratory Press; all rights reserved

Advanced Online Article. Cite this article as Cold Spring Harb Perspect Biol doi: 10.1101/cshperspect.a018853 
M. Götz et al.

et al. 2005; Brill et al. 2008; Colak et al. 2008; López-Juárez et al. 2013; Ninkovic et al. 2013; Walcher et al. 2013) and the basic helix-loophelix (bHLH) proneural TFs Ascl1, Neurog2, and Neurod1 (Parras et al. 2004; Kim et al. 2007, 2011; Brill et al. 2009; Roybon et al. 2009; Andersen et al. 2014). However, recent studies have also revealed some surprising differences in the mode of their function at the molecular level in the developing and adult brain (LópezJuárez et al. 2013; Ninkovic et al. 2013; Walcher et al. 2013; Andersen et al. 2014; Urban and Guillemot 2014).

\section{GLIOGENIC ENVIRONMENT IN THE ADULT BRAIN}

Why would adult neurogenesis require different or unique regulatory mechanisms? Foremost, a major difference between the developing and adult brain is the environment to which NSCs and their progeny are exposed. Radial glial cells in embryos are surrounded by many other radial glial cells and in close contact with the migrating neurons, whereas ependymal cells and a unique vascular network have become the direct neighbors of adult NSCs in the subependymal zone (SEZ) (reviewed in Fuentealba et al. 2012). These ependymal cells are not yet present in the embryonic brain as they are generated at late embryonic/early postnatal stages (Spassky et al. 2005; Paez-Gonzalez et al. 2011). Indeed, the proper formation of the ependymal layer appears to be relevant for the development of adult NSC hallmarks, even though cell autonomous or nonautonomous mechanisms are difficult to separate given the common origin of adult NSCs and ependymal cells from embryonic radial glia (Jacquet et al. 2009; PaezGonzalez et al. 2011). Likewise, adult NSCs in the dentate gyrus (DG) are surrounded by many glial cells that were not yet present at embryonic stages, such as mature oligodendrocytes and NG2 glia, or astrocytes. Indeed, these glial cells are largely generated at postnatal stages, whereas a majority of embryonic neurogenesis takes place in a privileged environment with neurogenesis as the default fate and gliogenesis still inhibited (Miller and Gauthier 2007) with radial glial cells acting as NSCs as virtually the only glial cells present (except some NG2 glia appearing at embryonic stages; for a recent review, see Dimou and Götz 2014).

In contrast, at all later stages in the postnatal and adult brain, gliogenesis is the predominant fate used outside the rather few neurogenic niches. In fact, transplantation studies have shown that cultured embryonic and adult progenitors, which show a strong neurogenic capacity in vitro, cannot efficiently generate neurons when grafted in the adult brain parenchyma, and instead, their fate is strongly skewed toward gliogenesis (Herrera et al. 1999; Cao et al. 2002; Enzmann et al. 2005; Hofstetter et al. 2005). Interestingly, the only places in the adult brain where transplanted cells can produce neurons are the areas of continuous neurogenesis such as the hippocampal DG (Shihabuddin et al. 2000). Moreover, although many studies have reported the occurrence of cells with a neurogenic capacity in normally nonneurogenic adult central nervous system (CNS) regions such as the spinal cord (Weiss et al. 1996; Shihabuddin et al. 1997, 2000; Yamamoto et al. 2001a,b), such cells are mostly incapable of regenerating neurons, and instead become glia or remain undifferentiated in vivo after injury (Yamamoto et al. 2001b; Ohori et al. 2006; Yang et al. 2006; Barnabé-Heider et al. 2010; for details, see Nakafuku and Grande 2013). This strong antineurogenic/gliogenic nature of the adult CNS is further highlighted by the fact that the capacity of neurogenic fate determinants such as Pax6, Ascl1, and Neurog2, which can efficiently reprogram nonneuronal cells into neurons in culture dishes, is very limited in vivo in the adult CNS (Buffo et al. 2005; Ohori et al. 2006; Grande et al. 2013; Torper et al. 2013). The molecular nature of this antineurogenic environment remains poorly understood, but probably involves a broad spectrum of humoral factors, such as inflammatory and immune cytokines, as well as extracellular matrix components specific to the mature CNS (for details, see Nakafuku and Grande 2013). Thus, adult neurogenesis has to overcome this intrinsically gliogenic environment, whereas this is not an issue in embryos. This is also not the 
case in the adult brain of many other vertebrates, in particular, fish and amphibians, in which adult neurogenesis is much more widespread compared with most mammalian species analyzed so far ( for a review, see Grandel and Brand 2013).

\section{CELL-CYCLE REGULATION}

Another aspect of adult NSCs diverging from embryonic counterparts is their cell-cycle regulation. Although most radial glial cells have a short cell cycle during development ranging between 10 and 18 h (Götz and Huttner 2005; Dehay and Kennedy 2007; Lange and Calegari 2010; Arai et al. 2011), most adult radial glial cells in the SEZ and subgranular zone (SGZ) of the DG have a much longer cell-cycle length ranging from several days to $2 \mathrm{wk}$ (Morshead et al. 1994; Bonaguidi et al. 2011; Lugert et al. 2012). This fits to their respective tasks — during embryogenesis, tissues and organs have to be formed in a relatively short period of time, so both stem cells as well as their downstream progenitors are engaged in active and fast proliferation. Already at embryonic day 13-15, some cells are set aside as adult stem cells and divide relatively infrequently (Furutachi et al. 2015), thereby starting early to follow the general hallmarks of adult stem cells utilizing rare divisions for avoiding the accumulation of genomic mutations or premature shortening of telomeres.

Interestingly, continuous live imaging in slice preparations of the lateral ganglionic eminence (LGE), the anlage of the later SEZ in the adult brain, revealed that radial glial cells facing the ventricle are the only cells self-renewing and possess the slowest cell-cycle progression (Pilz et al. 2013). Conversely, their progeny, a series of TAPs dividing in a symmetric proliferative mode, shorten their cell-cycle length at each subsequent round (Pilz et al. 2013). This is very different from the cerebral cortex with progenitors gradually lengthening the cell cycle in subsequent divisions (Götz and Huttner 2005; Lange and Calegari 2010). Thus, some hallmarks of adult NSCs, such as self-renewal and relatively slower cell-cycle progression, are already present in the embryonic radial glial cells in the region generating the adult NSCs at the lateral wall of the lateral ventricle (LV), diverging from other brain regions, such as the cerebral cortex, in which neurogenesis is terminated after development. The mechanisms underlying such region-specific cell-cycle control in NSCs in the embryonic LGE and adult SEZ are an important subject of future studies.

\section{GOING UP INSTEAD OF GOING DOWN- DISTINCT REGULATION OF NEUROGENIC FATE DETERMINANTS}

As mentioned above, adult NSCs are more akin to bona fide differentiated astrocytes and ependymal cells in their gene-expression patterns. Conversely, their embryonic counterparts cluster closely together with the cell fraction comprising the progeny of adult NSCs, namely TAPs and NBs (Beckervordersandforth et al. 2010). This difference is reflected in increasing expression levels of neurogenic fate determinants from adult NSCs to TAPs and NBs, whereas embryonic radial glia already possess as high levels of neurogenic fate determinants as adult NBs (Fig. 1). Importantly, adult NSCs do have significantly higher expression levels of $m R N A s$ for some of these fate determinants compared with bona fide astroglial cells from nonneurogenic regions such as the diencephalon (Beckervordersandforth et al. 2010). Thus, adult NSCs are primed for neurogenesis to some extent, but their progeny still needs to further up-regulate transcription of these fate determinants and acquire detectable protein levels to proceed to neurogenesis. Indeed, if this fails to occur, neurogenesis cannot proceed and cells are converted to gliogenesis instead (Ninkovic et al. 2013). Thus, controlled up-regulation of cellintrinsic neurogenic fate determinants in adult NSCs and their progeny is crucial for neuronal fate acquisition, in particular, in the otherwise strongly gliogenic/antineurogenic cell-extrinsic environment in the adult brain as described above. Conversely, the high levels of neurogenic fate in embryonic radial glia need to be rapidly down-regulated when TAPs and differentiating NBs are generated (Fig. 1) (see, e.g., Tuoc and Stoykova 2008). 
M. Götz et al.

A

\section{Embryonic neurogenesis}

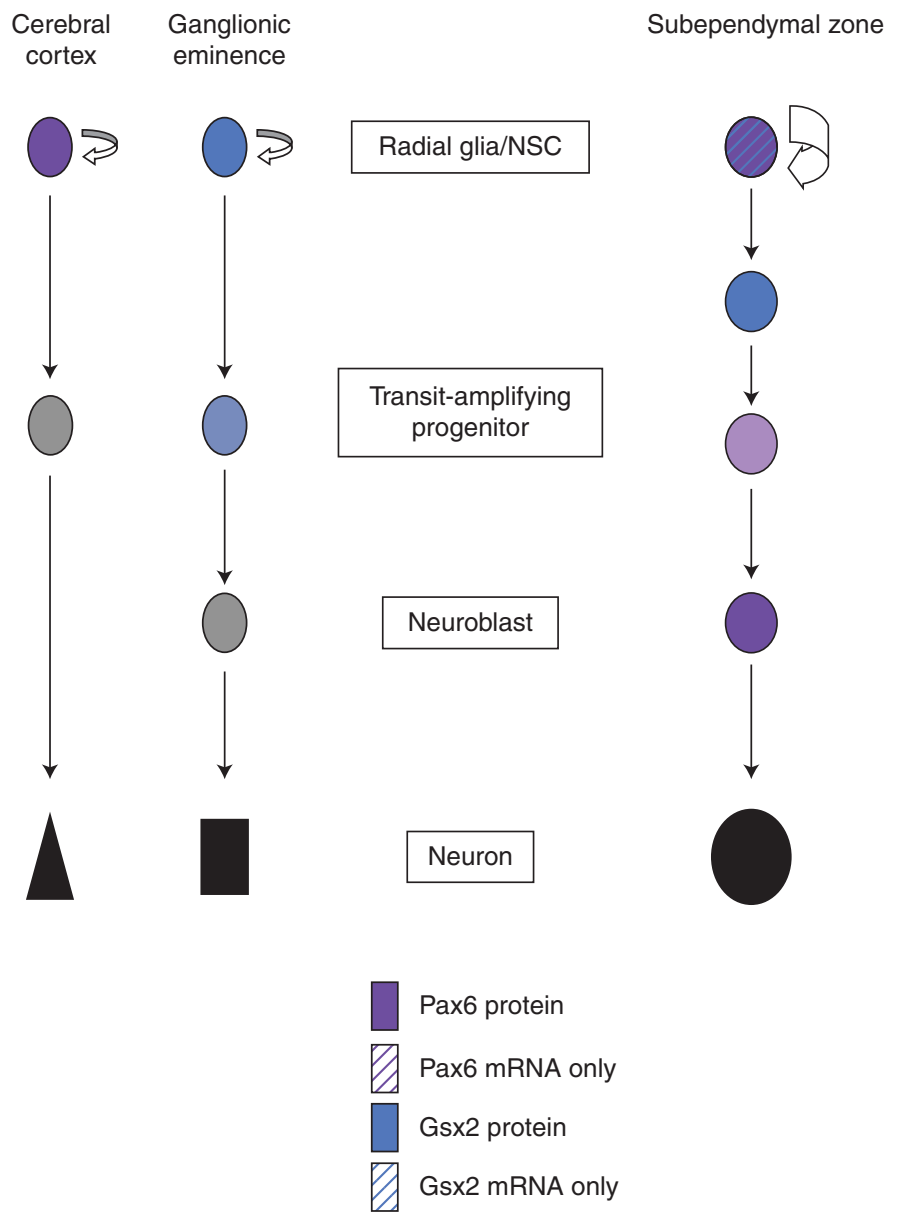

\section{Adult neurogenesis}

B

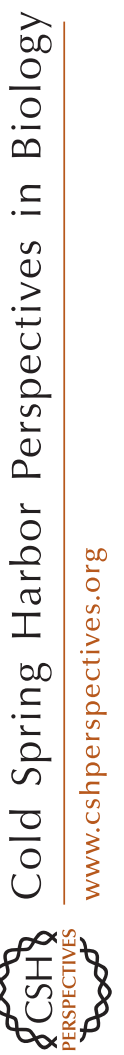

Figure 1. Distinct regulations of neurogenic fate determinants in embryonic and adult neurogenesis. $(A)$ The regulation of Pax6 (dark violet) and Gsx2 (blue) in embryonic neurogenesis in their respective regions with high protein levels already in the radial glia/neural stem cells (NSCs), which are then down-regulated in transitamplifying progenitors (TAPs) and neuroblasts (NBs). (B) Conversely, adult NSCs are only primed for neurogenesis with higher mRNA levels (dark violet and blue stripes) that are then up-regulated and translated into high-protein levels for Gsx2 in activated NSCs (blue cell) and for Pax6 in TAPs and neuroblasts.

The different levels of intrinsic neurogenic fate determinants in adult or embryonic NSCs have obvious consequences on the intrinsic fate bias when cells are isolated in a low-density primary culture system. In such a system, adult NSCs do not directly differentiate into neurons but rather generate a series of TAPs and NBs through cell divisions, which in turn up-regu- late the neurogenic fate determinants independent of their niche (Costa et al. 2011; Ninkovic et al. 2013). This is very different for embryonic radial glial cells, which already possess very high expression levels of neurogenic fate determinants and readily differentiate into neurons when put in low-density cultures (see, e.g., Heins et al. 2002; Haubst et al. 2004). Rather, 
these embryonic cells require extrinsic signals, such as fibroblast growth factor 2, to maintain them in a proliferative mode and inhibit direct neurogenesis (Qian et al. 1997, 2000). Thus, as embryonic radial glial cells have intrinsically high protein levels of neurogenic fate determinants, they are biased toward direct neuronal differentiation by default, whereas adult NSCs only possess baseline low levels of mRNAs and require a series of intermediate progenitor divisions to up-regulate protein levels before terminal neuronal differentiation.

These considerations highlight why adult NSCs may require the lower levels of neurogenic fate determinants, namely, to allow the maintenance of their multipotency. Although most embryonic radial glial cells behave like neuroblasts and readily differentiate into postmitotic neurons (Qian et al. 1997; Heins et al. 2002; Haubst et al. 2004), only some can be forced to acquire multipotency by addition of growth factors (Qian et al. 2000; Gabay et al. 2003; Hack et al. 2004) — fully consistent with their genomewide expression profile closely clustering to adult NBs (Beckervordersandforth et al. 2010). Conversely, adult NSCs are intrinsically multipotent and can still readily undergo gliogenesis as well as neurogenesis in vivo and in vitro (Hack et al. 2004; Menn et al. 2006; Benner et al. 2013; Ortega et al. 2013; Rafalski et al. 2013; Sohn et al. 2015). Thus, multipotency requires lowering the levels of fate determinants for one specific fate, suggesting that the tight control of fate determinants is a key strategy for the long-term maintenance of multipotent adult NSCs.

In this regard, it is interesting to consider differences between NSCs in the SEZ and SGZ of the DG. Some data suggest that SGZ NSCs may not be multipotent (Seaberg et al. 2002; Clarke et al. 2011) as they fail to generate oligodendrocytes under normal conditions (Jessberger et al. 2008; Bonaguidi et al. 2011; Encinas et al. 2011; Lugert et al. 2012). The SEZ certainly comprises oligodendrocyte progenitors (Hack et al. 2005; Menn et al. 2006), but to which extent these derive from NSCs is still under debate (Ortega et al. 2013; Rafalski et al. 2013). Importantly, the SEZ comprises a special signaling mechanism to suppress oligodendrogenesis, namely
BMP (bone morphogenetic protein), and thereby allows neurogenesis (Colak et al. 2008). On white matter injury, signals inhibiting the BMP pathway, such as chordin, are increased and thereby promote oligodendrocyte production at the expense of neurogenesis (Jablonska et al. 2010). Thus, BMP levels are tightly controlled in the adult SEZ to balance the neurogenic versus oligodendrogliogenic lineage (Gajera et al. 2010). As there is no oligodendrogliogenesis in the adult DG, interference with BMP signaling exerts a different function, namely, NSC self-renewal (Bonaguidi et al. 2008; Mira et al. 2010), although it is critical for DG formation and neurogenesis during development (Choe et al. 2013; Urban and Guillemot 2014). These considerations thus suggest that NSCs in the DG are more directed toward neurogenesis and accordingly would predict a higher expression level of neurogenic fate determinants already in the NSCs. Indeed, this is the case for Pax6, which is detectable by immunohistochemistry, that is, at protein levels, in radial glia-like NSCs in the rodent DG (Maekawa et al. 2005; Nacher et al. 2005; Hevner et al. 2006; Roybon et al. 2009), but not in their counterparts in the SEZ (Hack et al. 2005; Brill et al. 2008; Ninkovic et al. 2013). Notably, recent studies have revealed that there is also significantly less lineage amplification in the DG (Bonaguidi et al. 2011; Lugert et al. 2012) compared with the SEZ (Calzolari et al. 2015) at the clonal level in individual NSCs.

\section{MOLECULAR FATE DETERMINANTS IN EMBRYONIC AND ADULT NEUROGENESIS}

The considerations above thus highlight a major difference between embryonic and adult neurogenesis in the regulation of neurogenic fate determinants affecting the NSC lineage and potency. This is best understood for the homeodomain TFs Pax6, Gsx2, and Dlx (Dlx1 and Dlx2), and the bHLH TF Ascl1, which we will focus on below.

\section{PAX6}

As most neurogenic fate determinants are absent in differentiating postmitotic neurons, they 
M. Götz et al.

need to be rapidly down-regulated during the differentiation process. This is the case for Pax6 in embryonic neurogenesis as forced expression of Pax6 in all cells of the developing cerebral cortex, including neurons, elicits cell death (Berger et al. 2007). Indeed, Pax6 proteins are rapidly down-regulated and cleared out in intermediate/basal progenitors and subsequent neurons in the developing cerebral cortex and in other regions of its expression such as the spinal cord (Heins et al. 2002; Sugimori et al. 2007). Although transcriptional control is also implicated in this process, active protein degradation by Trim 11 has been shown to be critical for the fast down-regulation of the Pax6 protein (Tuoc and Stoykova 2008). Likewise, microRNAs regulate the protein level of Pax6 and other neurogenic fate determinants (Shibata et al. 2011; Chen et al. 2012; de Chevigny et al. 2012).

In adult neurogenesis, however, such regulators need to work the other way around, namely, ensuring up-regulation of Pax6 in progeny of NSCs, or restricting it at lower levels in undifferentiated NSCs. Indeed, there is a pronounced discrepancy between Pax6 mRNA (present) and protein (absent or low) levels in the SEZ at postnatal stages because of high levels of miR7a that repress Pax6 translation especially in this region (de Chevigny et al. 2012). This mechanism is used, on the one hand, to specify the region with highest Pax6 protein levels in NBs that generate dopaminergic periglomerular neurons (De Chevigny et al. 2012). Similar microRNA-mediated translational inhibition also likely contributes to restrict protein levels of other neurogenic fate determinants in the adult neurogenic lineage. Indeed, when the miR7a level is reduced, Pax6 protein comes up in widespread regions and cell types, including NSCs lining the LV (de Chevigny et al. 2012). Interestingly, several microRNAs are expressed in adult NSCs targeting an entire set of neurogenic TFs and hence allowing their coregulation (M Pusch, M Götz, and J Ninkovic, unpubl.). Thus, microRNAs seemingly act as guardians restricting the expression levels of Pax6 and other neurogenic fate determinants in NSCs, thereby ensuring that they do not rise prematurely.
As Pax6 exerts many roles in the developing brain, including patterning, cell cycle and cell division regulation, neurogenesis, and gliogenesis (Osumi et al. 2008; Georgala et al. 2011; Walcher et al. 2013), the molecular mechanisms by which it exerts its potent neurogenic action have only recently been unraveled (Fig. 2A). The neurogenic function of Pax6 is most obvious on forced expression of Pax6 that causes conversion of, for example, glial cells (astrocytes and/or oligodendrocyte progenitor cells) isolated from the postnatal cerebral cortex into functional neurons (Heins et al. 2002; Berninger et al. 2007; Ninkovic et al. 2013). Pax6 is even sufficient to instruct neuronal fate in glial cells after traumatic or ischemic injury in the adult brain in vivo (Buffo et al. 2005; Kronenberg et al. 2010; Grande et al. 2013), even though its downstream effector Neurog2 appears more efficient in some regions (Ohori et al. 2006; Grande et al. 2013).

Direct reprogramming also allows determining how Pax6 can exert this potent neurogenic function. Important findings have come out from analysis of differential roles of its three DNA-binding domains. Pax6 has a DNA-binding homeodomain, as well as a bipartite paired domain that binds DNAwith two separate modules, its amino-terminal PAI and carboxy-terminal RED subdomains (Fig. 2A). Importantly, splicing or internal transcriptional starts result in Pax6 isoforms lacking some of these DNAbinding domains. For example, the paired-less form of Pax6 lacks the entire paired domain and maintains only the homeodomain for DNA binding (Fig. 2A). As this form is not neurogenic at all, but rather regulates survival of olfactory bulb $(\mathrm{OB})$ dopaminergic interneurons (Fig. 2A) (Ninkovic et al. 2013; J Ninkovic and M Götz, unpubl.), this implies that targets of the paired domain must be involved in regulation of neurogenic effector genes. Recent work has further unraveled that exclusively targets of the PAI domain are necessary and sufficient to regulate a neurogenic fate in the developing forebrain and spinal cord (Walcher et al. 2013; Huettl et al., in press). This has been observed in experiments with forced expression of plasmids or in mouse mutants with Pax6 lacking the PAI 
A

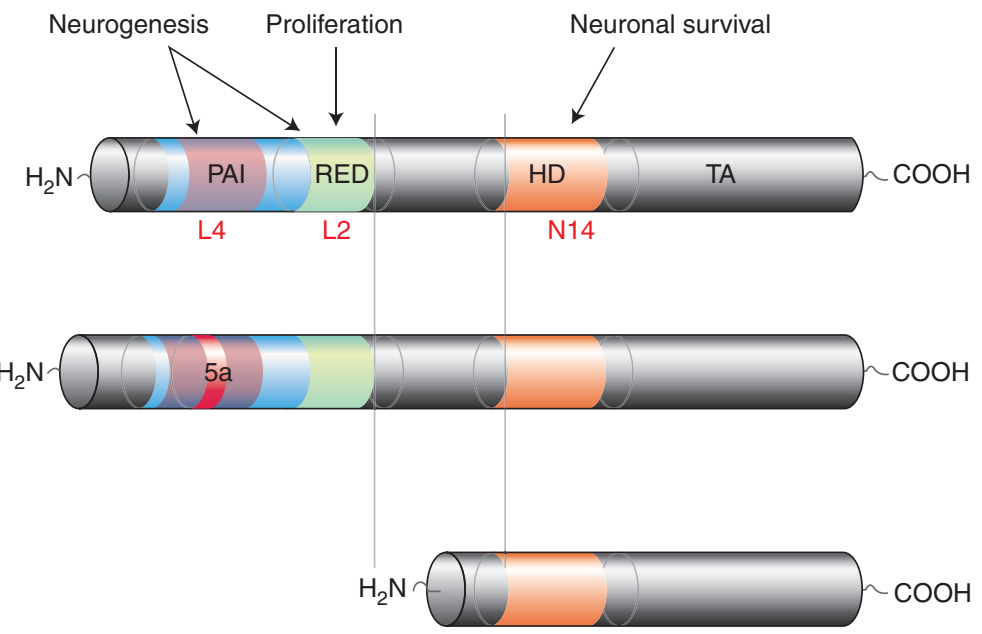

\section{B}

$$
\begin{array}{lll}
+ \text { Brg1 } & - \text { Brg1 } & + \text { Brg1 } \\
+ \text { Pax6 } & + \text { Pax6 } & - \text { Pax6 }
\end{array}
$$

$$
\begin{aligned}
& + \text { Brg1 } \\
& + \text { Pax6 }
\end{aligned}
$$$$
\begin{aligned}
& - \text { Brg1 } \\
& + \text { Pax6 }
\end{aligned}
$$

$+\mathrm{Brg} 1$
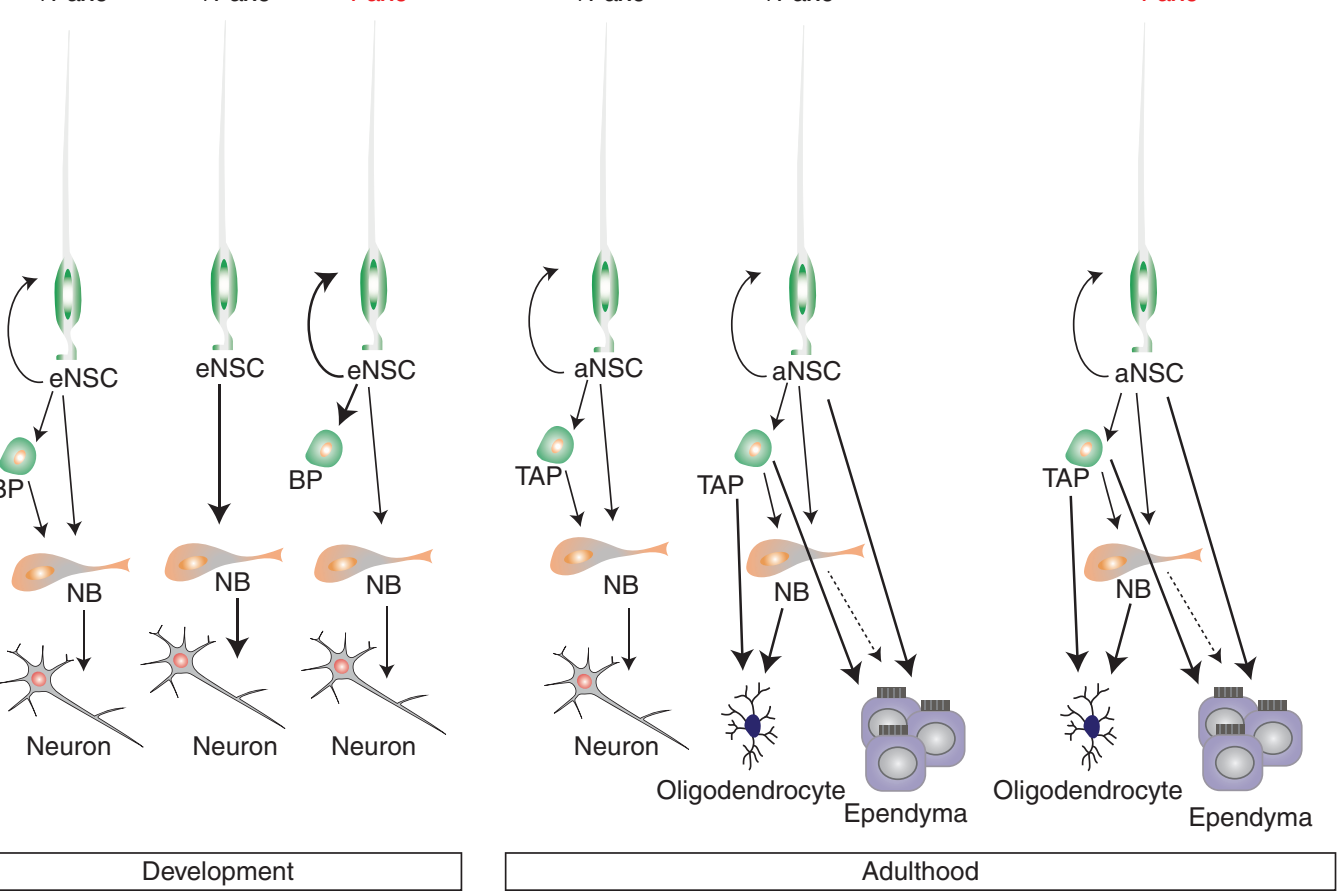

Development

Adulthood

Figure 2. The function of Pax6 in embryonic and adult neurogenesis. (A) Schematic drawings depict the different Pax6 isoforms with the respective DNA-binding domains in color. Note that on insertion of the exon 5a (ii) the DNA binding of the PAI subdomain is abolished and the paired-less form of Pax6 (iii) lacks both DNA-binding domains of the paired, the PAI, and the RED domain. Although the paired-less domain is not neurogenic at all, it is required for survival of dopaminergic interneurons in the olfactory bulb. The PAI domain is essential for embryonic and adult neurogenesis, whereas the RED domain is dispensable for embryonic but not adult neurogenesis. (B) The interaction of Pax6 with the Brg1 containing BAF chromatin remodeling complex and its distinct roles in embryonic (left) and adult (right) neurogenesis. eNSC, Embryonic neural stem cell; aNSC, adult NSC; BP, basal progenitor; TAP, transient amplifying progenitor; NB, neuroblast. 
M. Götz et al.

subdomain DNA binding and thereby abolishing its neurogenic effect (Haubst et al. 2004; Walcher et al. 2013). This is the case for the Pax6 splice variant including exon5a that interferes with DNA binding of the PAI domain (Fig. 2Aii) (Haubst et al. 2004) and a form of Pax6 with a point mutation in the PAI subdomain, which, abolishes selectively binding to PAI, but not RED consensus sites (L4 in Fig. 2Ai), which also interferes with neurogenesis both in vivo in the respective mouse mutant as well as in vitro in forced expression experiments using this mutant form of Pax6 (Walcher et al. 2013). Conversely, a mutation in the RED domain does not interfere with endogenous neurogenesis in vivo or with forced neurogenesis in embryonic radial glial cells in vitro (Walcher et al. 2013). These experiments have thus identified the PAI domain as the sole regulator of neurogenesis mediated by Pax6 in the developing brain, and the above selective mutants now allowed determining the genes selectively regulated by this domain in the developing mouse cerebral cortex (Walcher et al. 2013). Intriguingly, however, Pax6-mediated neurogenesis from adult SEZ cells also requires a functional RED domain. Forced expression of RED or PAI domain mutant forms cannot induce neurogenesis in adult NSCs of the SEZ in vitro or in vivo (S Petricca, J Ninkovic, and M Götz, unpubl.). Thus, these data imply the necessity of an additional level of target gene regulation requiring both subdomains of the paired domain to elicit neurogenesis in cells of the adult, but not the developing forebrain.

Additional requirements for Pax6 to mediate neurogenesis in the adult SEZ have also been identified at the chromatin level. In adult SEZ neurogenesis, Pax6 requires interaction with the Brg1-containing BAF complex of the SWI/SNF family of chromatin remodeling factors (Ninkovic et al. 2013), although this is dispensable for the neurogenic function of Pax6 during development (Fig. 2B). Conditional deletion of Brg1, the essential ATPase subunit of the BAF complex, in adult NSCs severely interferes with SEZ-derived neurogenesis. This phenotype is phenocopied entirely by conditional deletion of Pax6. Importantly, genes that fail to be up- regulated on Brg1 deletion are virtually all regulated by Pax6 (Ninkovic et al. 2013). Thus, Pax6 and Brg1-containing BAF complex physically interact and up-regulate Pax6 target genes. The downstream effectors from this complex comprise a self-amplifying cross-regulatory network of three neurogenic TFs (Pou3f2/4, Sox4/11, and Nfia/b), all of which are direct targets of Pax6 and Brg1, as well as of each other (Ninkovic et al. 2013). This cross-regulatory network is turned on by Pax6 interacting with the Brg1containing BAF complex, and, subsequently, each member is required to achieve sufficiently high levels of their own and their target gene expression that ultimately promote neuronal differentiation. Indeed, deletion of any one of these factors results in lower expression levels of the others, ultimately failing to reach the critical threshold for stabilizing a neuronal fate (Ninkovic et al. 2013). Thus, this network is critical to raise the levels of neurogenic fate determinants in the TAPs and NBs sufficiently high for stabilizing neuronal fate and differentiation.

Conversely, such mechanisms are not required for fate stabilization during development when neurogenesis occurs in a neurogenic environment. Indeed, when neurogenesis fails, cells rather remain as radial glial cells and are not converted to gliogenesis (Osumi et al. 2008; Guérout et al. 2014), which is not yet actively supported by the environment at early stages. Accordingly, of the Pax6-driven gene network in adult neurogenesis, only Pou3f4 is significantly down-regulated in the embryonic Pax6 mutant telencephalon (Walcher et al. 2013), whereas most of the others are not expressed or regulated at this stage. Likewise, deletion of Brg1 does not exert overt neurogenesis defects, but rather affects the NSC self-renewal in development (Matsumoto et al. 2006; Lessard et al. 2007) and hence does not phenocopy the Pax6 deletion in embryonic neurogenesis (Heins et al. 2002; Haubst et al. 2004). Taken together, only in adult neurogenesis, both subdomains of the paired domain of Pax6 regulate neurogenesis, and, only in adult neurogenesis, Pax6 needs to associate with a potent chromatin remodeling complex to activate a self-amplifying 
downstream effector network for neurogenesis (Fig. 2).

\section{GSX2, ASCL1, and DLX}

Gsx2 is another prime example of neurogenic fate determinants that coordinate multiple aspects of progenitor behavior in both embryos and adults. During development, it is broadly expressed in the ventricular zone of the ventral telencephalon, including the LGE, median ganglionic eminence (MGE), and ventral septum (Fig. 3A) (Corbin et al. 2000; Toresson et al. 2000; Toresson and Campbell 2001; Yun et al. 2001, 2003). In particular, its dorsal limit is adjacent to the ventral border of the pallial Pax6 ${ }^{+}$ domain with a narrow overlap, and cross-repressive interactions between Gsx2 and Pax6 establish the pallial-subpallial boundary (Toresson et al. 2000; Yun et al. 2001). Moreover, proliferation of LGE progenitors is severely attenuated in Gsx2 mutant embryos, leading to the diminished formation of the $\mathrm{OB}$, the striatum, and other basal ganglia nuclei, and a part of the amygdala (Toresson et al. 2000; Yun et al. 2001; Stenman et al. 2003; Waclaw et al. 2010). Such proliferation deficits occur in areas beyond the aberrantly expanded Pax6-expressing territory, indicating that Gsx2 regulates progenitor proliferation independently of its role in patterning.

Interestingly, the initially broad Gsx2 expression in early embryos gradually becomes refined to a high dorsal and low ventral gradient within the LGE at later stages (Stenman et al. 2003). The high Gsx2-expressing region defines the dorsal (d) LGE that serves as a major source of embryonically generated OB interneurons, whereas the more ventral $(\mathrm{v})$ region (vLGE) is responsible for the production of striatal projection neurons (Stenman et al. 2003; Waclaw et al. 2009). A recent study has shown a similar gradient of Gsx2 expression in the adult SEZ; $\mathrm{Gsx}^{+}$NSCs are highly enriched in the dorsolateral $(\mathrm{dl})$ corner, whereas such cells are much less frequent in other SEZ subdomains (Fig. 3B) (López-Juárez et al. 2013). Gsx1, a close homo$\log$ of Gsx2, is expressed in these Gsx2-negative regions, and another homeodomain TF Nkx2.1 is expressed in the ventral-most region (LópezJuárez et al. 2013). Moreover, dorsal to the $\mathrm{Gsx}^{+}$dlSEZ, there is a narrow subdomain between the overlaying corpus callosum and LV (dorsal roof [dr] SEZ) in which Pax6-expressing cells reside. Thus, the adult SEZ is divided into at least four molecularly distinct subdomains, the Pax6 ${ }^{+}$drSEZ, Gsx2 ${ }^{+} / \mathrm{Pax}^{+}$dlSEZ, Gsx $1^{+}$ lateral (1) and medial (m) SEZs, and $\mathrm{Gsxl}^{+} /$ $\mathrm{Nkx} 2.1^{+}$ventral (v) SEZ. This domain organization mirrors that in the embryonic brain (Fig. 3B). In fact, fate-mapping studies using various Cre-expressing mice suggest the direct lineage relationships between embryonic progenitor domains and adult SEZ subdomains (Kohwi et al. 2005'; Willaime-Morawek et al. 2006; Young et al. 2007; Merkle et al. 2014). These findings support the idea that, like in embryonic neurogenesis, the regional identity of NSCs in the adult SEZ plays a role in generating the diversity of adult-born OB neurons. Further studies have provided evidence supportive of this view. NSCs residing in distinct regions of the SEZ produce overlapping but distinct subsets of $\mathrm{OB}$ interneurons at birth and, to some extent, in adults as well (Merkle et al. 2007, 2014). Moreover, inactivation of Pax6 and Gsx2 leads to a loss of distinct subsets of $\mathrm{OB}$ neurons (tyrosine hydroxylase ${ }^{+}$and calretinin ${ }^{+}$glomerular neurons, respectively, among others) (Hack et al. 2005; Kohwi et al. 2005; Brill et al. 2008; López-Juárez et al. 2013; Ninkovic et al. 2013).

Nevertheless, there are significant differences in the mechanisms by which the regional identity of progenitors is regulated in embryos and adults. Inactivation of Gsx2 in embryos results in compensatory expansion of both the dorsal Pax6 ${ }^{+}$and ventral Gsx1 ${ }^{+}$domains (Fig. 3A, lower panels) (Toresson et al. 2000; Toresson and Campbell 2001; Yun et al. 2001). Such changes, however, do not occur in adult Gsx2 mutants (Fig. 3B) (López-Juárez et al. 2013). Likewise, although ectopic expression of Gsx2 suppresses Pax6 and Gsx1, and overexpressed Gsx1 inhibits Gsx2 expression in the developing telencephalon (Waclaw et al. 2009; Pei et al. 2011), ectopic expression of Gsx1 or Gsx2 does not alter the domain-specific expression of other TFs in the adult SEZ (López-Juárez 
M. Götz et al.

A

A
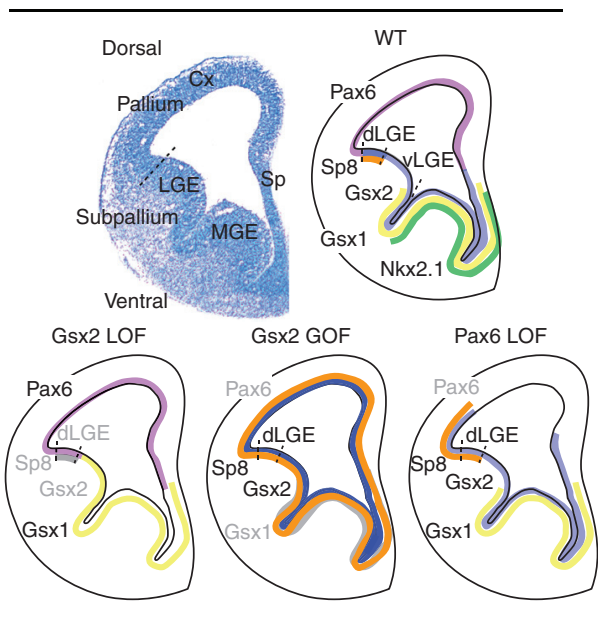

C

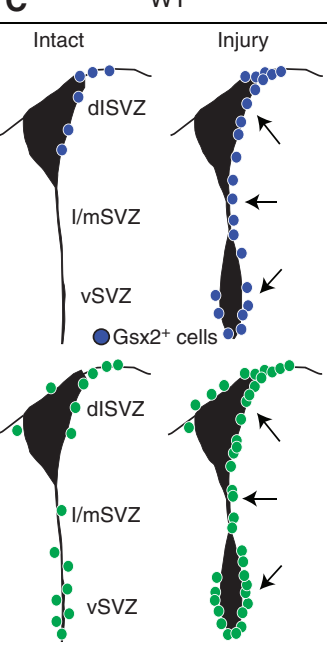

Dlx2 $2^{+}$and $\mathrm{Ki} 67^{+}$cells
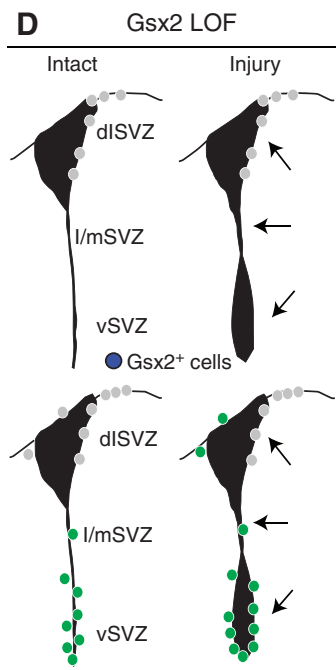

$\mathrm{Dl} \times 2^{+}$and $\mathrm{Ki} 67^{+}$cells
B
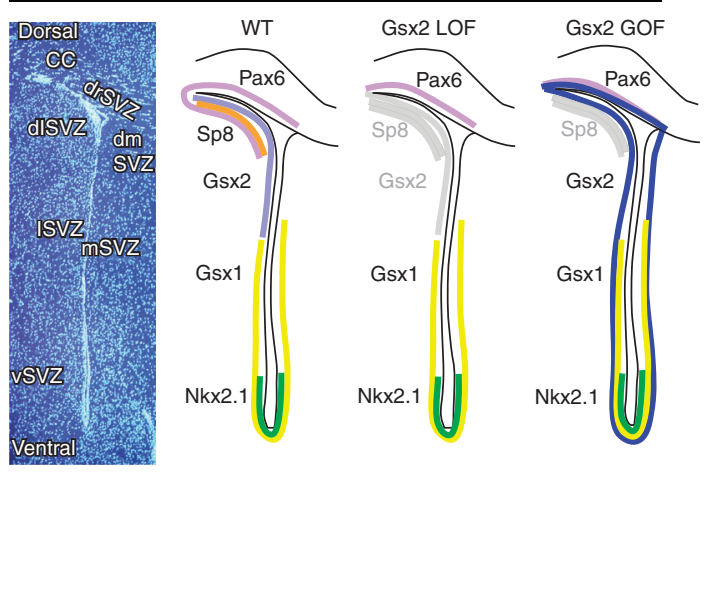

Figure 3. Region-specific gene expression in the embryonic brain and adult SEZ. $(A, B)$ The expression patterns of Pax6, Gsx2, Gsx1, and Nkx2.1 along the dorsoventral axis of progenitor domains in embryos $(A)$ and the adult SEZ (B). The expression pattern in the wild-type (WT) and loss-of-function (LOF) and gain-of-function (GOF) mutants of Gsx2 and Pax6 are schematically depicted. $(C, D)$ Essential role of Gsx2 in injury-induced neurogenesis in the adult SEZ. The expression patterns of Gsx2 (upper panels), and Dlx and Ki67 (lower panels) in the adult SEZ of the wild-type $(C)$ and Gsx2 LOF mice $(D)$ under intact uninjured (left) and injured (right) conditions. In the WT mice, more Gsx $2^{+}$cells appear in its normal expression domain (dlSVZ) and also ectopically in the lateral (1), medial (m), and ventral (v) SEZs in response to injury ( $C$, upper panels). Such Gsx2 induction accompanies the up-regulation of $\mathrm{Dlx}^{+}$and $\mathrm{Ki}^{+} 7^{+}$cells, reflecting injury-stimulated neurogenesis ( $C$, lower panels). In contrast, the up-regulation of $\mathrm{Dlx}^{+}$and $\mathrm{Ki}_{67}{ }^{+}$cells does not occur in Gsx2 LOF mice in either dlSVZ or other SEZ subregions in which Gsx2 is not required for neurogenesis under normal conditions ( $C$, lower panels). CC, Corpus callosum; Cx, cerebral cortex; LGE, lateral ganglionic eminence; MGE, medial ganglionic eminence; Sp, septum; d, dorsal; dl, dorsolateral; dr, dorsal roof. 
et al. 2013; A López-Juárez and M Nakafuku, unpubl.). Thus, once the regional specificity is established during development, it appears that cross-repressive interactions between these patterning TFs do not operate any more, and the molecular profile of distinct adult NSC subgroups is maintained independently from each other.

Another interesting finding is that Gsx2 is involved in adult-specific regulation of neurogenesis, namely, stimulation in response to injury (Fig. 3C,D). Numerous previous studies have shown that a variety of brain insults, including ischemia, trauma, and neurodegeneration, up-regulate continuous baseline neurogenesis in the adult SEZ (reviewed in Nakafuku and Grande 2013). A recent study has shown that the normally dorsally restricted expression of Gsx2 is expanded to broader SEZ subdomains in response to hypoxia-ischemia and excitotoxic acute insults (Fig. 3C) (López-Juárez et al. 2013). Moreover, deletion of Gsx 2 in NSCs halts injury-induced up-regulation of neurogenesis across SEZ subdomains, including those that do not normally depend on Gsx2 for continuous neurogenesis (Fig. 3D). These results show that injury-induced neurogenesis is not just an accelerated version of continuous neurogenesis in the intact brain, but rather is controlled by distinct mechanisms.

Similarities and differences can also be found in the role of Gsx2 in OB neurogenesis during development and adulthood. Gsx2 mutant progenitors in embryos and adults are both defective in producing OB interneurons (Stenman et al. 2003; Yun et al. 2003; Waclaw et al. 2009; López-Juárez et al. 2013). An important difference, however, is that germline Gsx2 mutants show a severe loss of many dLGE-derived $\mathrm{OB}$ interneuron subtypes including both $\mathrm{Sp} 8^{+}$ and $\mathrm{Pax}^{+}{ }^{+}$neurons (Stenman et al. 2003; Yun et al. 2003), whereas adult Gsx2 deletion causes a loss of a small subset of OB interneurons, mainly $\mathrm{Sp} 8^{+}$granule cells and periglomerular layer neurons, but not $\operatorname{Pax}^{+}$periglomerular layer neurons or the majority of $\gamma$-aminobutyric acid (GABA)-ergic granule cells (López-Juárez et al. 2013). Thus, the role of Gsx2 in OB neurogenesis appears more limited in adults than in embryos. Interestingly, $\mathrm{Pax}^{+}$cells remain in the dorsal roof region of the adult SEZ, whereas those in the adjacent dlSEZ where Gsx2 ${ }^{+}$NSCs reside and overlap with $\mathrm{Pax}^{+}$cells are lost in adult Gsx2 mutants. These Pax6/ Gsx2-coexpressing cells are reminiscent of cells found as a narrow stripe at the pallial-subpallial boundary of the embryonic telencephalon (Stenman et al. 2003). Thus, Gsx $2^{+}$adult stem cells in the dISEZ may be a descendant of this specific subpopulation of $\mathrm{Gs} \times 2^{+}$progenitors in embryos.

Differences in embryos and adults are also evident in the temporal control of Gsx 2 expression and its action during the course of the lineage progression of stem cells. During development, most, if not all, dLGE progenitors continue to express Gsx2 from early to late stages (Stenman et al. 2003; Waclaw et al. 2009). In the adult SEZ, however, its expression is confined to a subpopulation of NSCs in the dISEZ. Detailed marker analysis has further revealed that Gsx2 is first turned on when quiescent NSCs are activated and recruited to the cell cycle, and subsequently carried on in a subset of TAPs. It is eventually turned off when TAPs start expressing Dlx and differentiating into NBs (Fig. 4A) (López-Juárez et al. 2013). Consistent with this temporal expression pattern, conditional inactivation of Gsx2 blocks the transition from NSCs to TAPs, a crucial first step in the lineage progression toward neurogenesis. Paradoxically, constitutive overexpression of Gsx2 also blocks neurogenesis at the same step, indicating that Gsx2 needs first to be turned on and subsequently turned off for stem cells to generate TAPs and NBs. Thus, Gsx2 acts as a gatekeeper of adult neurogenesis by keeping NSCs in check and limiting their recruitment toward neurogenesis. Such a tight control by Gsx 2 is not evident in embryos. Although the requirement of Gsx2 for the generation of secondary progenitors is the same, overexpression of Gsx2 stimulates, rather than inhibits, neurogenesis in the embryonic telencephalon (Waclaw et al. 2009; Pei et al. 2011). Moreover, although inactivation and overexpression of Gsx2 leads to enhanced and attenuated oligodendrogenesis, respectively, in embryos (Chapman et al. 2013), such fate 
M. Götz et al.

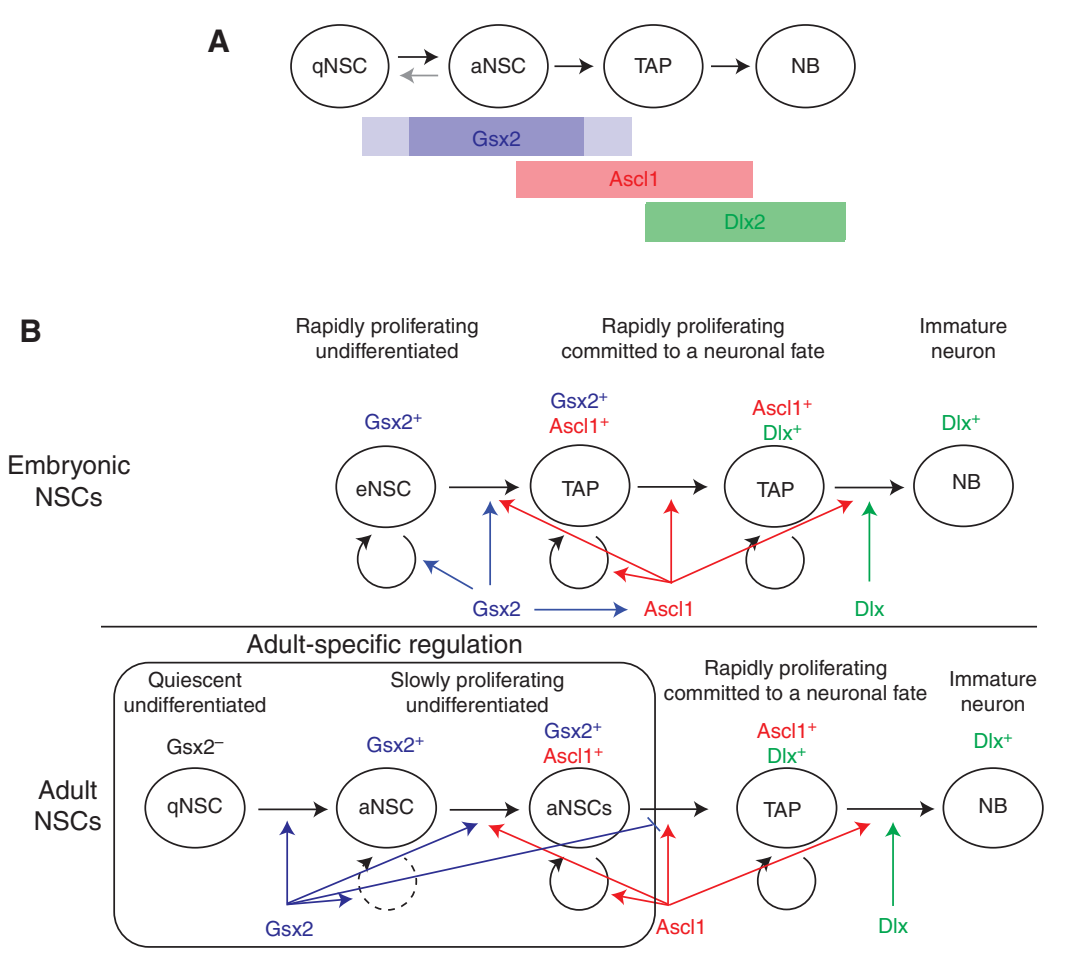

Figure 4. Different modes of action of Gsx2 and its downstream neuronal fate determinants in embryonic and adult NSCs. (A) The expression of Gsx2, Ascl1, and Dlx during the lineage progression of adult subependymal zone (SEZ) NSCs. (B) The expression and function of Gsx2 and its downstream regulators Ascl1 and Dlx in embryonic dLGE progenitors (eNSCs) (upper panel) and adult SEZ NSCs (lower panel). Gsx2 regulates adultspecific regulatory steps, the recruitment of quiescent stem cells (qNSCs) to activate slowly cycling NSCs (aNSCs), and the subsequent transition from aNSCs to transient-amplifying progenitors (TAPs) and neuroblasts (NBs).

changes are not observed in adult Gsx2 mutants (López-Juárez et al. 2013), suggesting that the primary role of Gsx2 in adults is the recruitment of multipotent NSCs into the cell cycle, a step before neuron-glia fate decisions. These results support the aforementioned notion that embryonic progenitors are prone to differentiation, whereas adult NSCs are under additional controls.

Similarities and differences are also found between embryos and adults in terms of the mechanisms downstream from Gsx1/2. In the embryonic telencephalon, the bHLH factor Ascl1 and the homeodomain factor Dlx (Dlx1 and Dlx2) act as major neurogenic TFs downstream from Gsx1/2 (Fig. 4B). Their expression is severely attenuated in widespread regions of the developing ventral forebrain in Gsx2 germ- line mutants and almost completely lost in the dLGE in Gsx1/2 double mutants (Corbin et al. 2000; Toresson et al. 2000; Toresson and Campbell 2001; Yun et al. 2001; Wang et al. 2009). Conversely, ectopic expression of either Gsx1 or Gsx2 can induce robust expression of Ascl1 and Dlx in broad telencephalic regions (Waclaw et al. 2009; Pei et al. 2011). Similar to Gsx1/2 mutants, generation of interneurons is significantly attenuated in the OB of Ascll (Casarosa et al. 1999; Parras et al. 2004; Long et al. 2007) and Dlx (Bulfone et al. 1998; Long et al. 2003, 2007) mutant mice. Finally, genetic analysis of single and compound mutants have shown that the expression of Ascl1 and Dlx1/2 are largely preserved in both Dlx1/2 and Ascl1 mutant brains, respectively, and that these TFs act through parallel and overlapping pathways in 
the generation of $\mathrm{OB}$ and other forebrain neurons during development (Bulfone et al. 1998; Casarosa et al. 1999; Long et al. 2007, 2009). A similar upstream-downstream relationship between Gsx1/2 and Ascl1/Dlx is found in the adult brain. The expression of Ascll and Dlx is lost in the dlSEZ of conditional Gsx2 mutants (López-Juárez et al. 2013), and conditional inactivation of Ascl1 results in a severe loss of neurogenesis in the adult SEZ (Andersen et al. 2014). Inhibition of Dlx activity in the SEZ by its dominant-negative form also results in attenuated $\mathrm{OB}$ neuron production (Brill et al. 2008; Colak et al. 2008). Altogether, these results show that a common genetic cascade (Gsx2Ascl1-Dlx) operate in controlling OB neurogenesis in embryos and adults.

Closer examinations of these mutant animals, however, have revealed important differences. Most notably, the dependency on Ascl1 appears distinct between embryonic and adult stages. Although the total number of OB interneurons generated by the end of embryogenesis is significantly reduced in Ascl1 knockout mice, $\sim 1 / 3$ and $\sim 2 / 3$ of the GABAergic neurons in the glomerular layer and granule cell layers, respectively, are still present in the mutants (Parras et al. 2004). In fact, the proliferative activity of stem/progenitor cells in the SEZ is, although slightly reduced compared with wild-type animals, preserved at birth in Ascl1 mutants (Parras et al. 2004). In contrast, few proliferative cells remain in the SEZ and rostral-migratory stream (RMS), and the production of new OB neurons is almost complexly lost when Ascl1 is conditionally inactivated in the SEZ at the adult stage, demonstrating an essential role of Ascl1 in adult neurogenesis (Andersen et al. 2014; M Simic, F Guillemot, and M Nakafuku, unpubl.). Thus, NSCs responsible for $\mathrm{OB}$ neurogenesis become more dependent on Ascl1 while transitioning from embryonic to adult stages, which is opposite to the dependency on Gsx2 (more dependent on Gsx2 in embryos than adults) described above. This could be caused by differences in the OB neuron subtypes produced at distinct stages (Batista-Brito et al. 2008), or, alternatively, genes that act redundantly with Gsx2 and Ascl1 operate differentially in embryos and adults.
Further investigations of the exact dependency of various OB neuronal subtypes on Ascl1 and Gsx2 at distinct stages will provide a clearer picture on the mechanisms of regulation of $\mathrm{OB}$ neurogenesis.

Gain-of-function experiments have also revealed an interesting difference in the functional relationships between Gsx2 and Ascl1/Dlx. Misexpression of Gsx2 (and Gsx1) robustly induces Ascl1 and Dlx expression in widespread regions of the developing telencephalon (Waclaw et al. 2009; Pei et al. 2011). Its overexpression in adult NSCs, however, rather suppresses their expression, thereby keeping stem cells at a slowly dividing undifferentiated state (Fig. 4B) (López-Juárez et al. 2013). Moreover, recent studies further suggest that complex cross talks between Gsx2 and Ascl1 play a role in determining whether stem cells remain undifferentiated or proceed to neurogenesis (M Simic, F Guillemot, and M Nakafuku, unpubl.). Thus, although a similar genetic pathway (Gsx2Ascl1-Dlx) is used in embryos and adults, the mode of their interactions is different in the two systems.

\section{NEUROTRANSMITTER SIGNALING IN EMBRYONIC AND ADULT NEUROGENESIS}

So far, we reviewed largely the differences and similarities of intrinsic regulators of NSCs and neurogenesis, but of course the same applies to extrinsic signaling. Much of the signaling sources and factors change from embryonic to adult neurogenesis, but some of the usual suspects are also present and potently active at both stages. This is, for example, the case for Wnt or BMP signaling (for recent review, see Urban and Guillemot 2014). Interestingly, Wnt promotes proliferation of NSCs and neuronal differentiation both at embryonic and adult stages, whereas BMP maintains quiescence of mostly adult SGZ NSCs (Urban and Guillemot 2014). As this review already excellently surveyed the distinct function of such key growth factors, we will briefly review here the differences and similarities of the key neurotransmitters, GABA and glutamate, in embryonic and adult neurogenesis. 
M. Götz et al.

Differences in structural and cellular features between embryonic and adult brain tissue determine how humoral factors influence NSC biology. In the embryo, the key tissue elements, such as blood-brain barrier (Hagan and BenZvi 2015), astrocyte (Jacobsen and Miller 2003; Rowitch and Kriegstein 2010) and oligodendrocyte cells (Kessaris et al. 2006), or stable neuronal circuitry (Kelsch et al. 2012; Luhmann et al. 2014), are either not present or undergoing development. Absence of these elements is bound to influence the way humoral factors, such as growth factors or neurotransmitters, can affect cellular processes. For example, astrocytes are able to both release and buffer tonic neurotransmitters (for review, see Parpura and Verkhratsky 2012), and such functions can be expected in aNSCs as well because they express neurotransmitter transporters (Liu et al. 2006; Ninkovic et al. 2007; Beckervordersandforth et al. 2010). The differences in cellular factors, such as absence of dense astroglial networks in the embryo, as well as in expression of different neurotransmitter receptors between adult and embryonic brain are likely to define differential effects of neurotransmitter actions on the NSCs as we will discuss below with the emphasis on NSC proliferation (for recent review on neurotransmitter influencing neuronal migration, see Luhmann et al. 2015) for the two major neurotransmitters, GABA and glutamate, as they are present in most brain regions and allow crossregional comparison.

\section{GABA}

GABA is a major neurotransmitter that acts on a multitude of receptors with many subunits and splice variants. GABAergic receptors fall into two major groups, the ionotropic GABA-activated chloride channels that typically hyperpolarize neurons in the adult brain (Olsen and Sieghart 2008) and the metabotropic $\mathrm{GABA}_{B}$ receptors that are coupled to $G$ proteins and (when coupled with $\mathrm{Gi} /$ o proteins) reduce calcium and increase potassium conductance via voltage-gated calcium and inwardly rectifying potassium channels, respectively (Bowery et al. 2002). Both types of receptors are expressed on embryonic and adult neural progenitors (Tozuka et al. 2005; Renzel et al. 2013; Giachino et al. 2014).

Higher expression of the $\mathrm{Na}^{+}-\mathrm{K}^{+}-2 \mathrm{Cl}^{-}$ cotransporter (NKCC1) in neural stem and progenitor cells as well as young neurons increase the chloride concentration inside the cell and reverses the effects of $\mathrm{GABA}_{\mathrm{A}}$ receptors (Li et al. 2002), making them activate because of the depolarization resulting from chloride ion efflux instead of the influx in mature neurons that results in hyperpolarization. Accordingly, activation of $\mathrm{GABA}_{\mathrm{A}}$ receptors in neural progenitors leads to chloride efflux, thus depolarizing both the embryonic cerebral cortex and adult SEZ progenitors (LoTurco et al. 1995; Wang et al. 2003), which, in turn, leads to their activation via increased calcium influx (Young et al. 2010). Despite this shared mode of action, GABA exerts different actions on proliferation of embryonic and adult NSCs. In the adult brain, GABA inhibits activation of aNSCs in SGZ (Song et al. 2012) and reduces the number of proliferating cells in SEZ (Liu et al. 2005). In embryos, however, activation of $\mathrm{GABA}_{\mathrm{A}}$ promotes proliferation of NSCs located in the ventricular zone (VZ), while it decreases cell proliferation of basal progenitors in the subventricular zone (SVZ) (Haydar et al. 2000) and in the peripheral neural crest stem cells (Andang et al. 2008). This opposing effect of GABA on different embryonic progenitors may be a result of intrinsic differences in the expression of GABAergic receptor subunits, or they may result from differential GABAergic inputs. Such regional differences in GABA sources are observed even between the two adult neurogenic niches, in which GABA in the SGZ is provided by local interneurons (Song et al. 2012), whereas neuroblasts release tonic GABA in the SEZ (Liu et al. 2005). Phasic actions are very local and short lasting, whereas tonic (also called volumetric) release may affect greater areas and for longer times. The differences of GABAergic action in between embryonic and adult NSCs is curious considering the shared mechanisms of action. GABAergic stimulation decreases DNA synthesis in embryonic progenitors (LoTurco et al. 1995), a mechanism that 
was linked to phosphorylation of HA2X histone in the adult SEZ (Fernando et al. 2011).

This difference in GABAergic action on embryonic versus adult NSCs is further corroborated by the effects of $\mathrm{GABA}_{\mathrm{B}}$ receptors. In the adult SGZ, pharmacological or genetic ablation of $\mathrm{GABA}_{\mathrm{B}}$ receptors in aNSCs promotes their proliferation, suggesting that signaling from $\mathrm{GABA}_{\mathrm{B}}$ receptors is antiproliferative (Giachino et al.2014). In contrast, there is less proliferation in neurospheres derived from $\mathrm{GABA}_{\mathrm{B}} \mathrm{R} 1$ subunit knockout mice or after blocking $G_{A B} A_{B}$ receptors, suggesting that $G_{A B A}$ acts as a pro-proliferative agent in embryos (Nakamichi et al. 2009).

\section{Glutamate}

Regulation by the excitatory neurotransmitter glutamate is rather complex. This is given, among other factors, by the diversity of glutamate receptors and their specific spatial and temporal distribution patterns in neural progenitors (Melchiorri et al. 2007). There are two classes of ionotropic receptors (pharmacologically classified as AMPA/kainate and NMDA receptors) composed of 18 different gene products (Traynelis et al. 2010) and eight metabotropic, G-protein-coupled receptors (mGluR1-8) in three groups, groups I to III (Collingridge et al. 2009).

Metabotropic glutamate receptors regulate neural stem and progenitors in a more straightforward fashion than the ionotropic receptors; however, there are some marked differences regarding glutamatergic actions in embryonic versus adult neurogenesis. Blockage or ablation of mGluR5 $\mathrm{G}_{\mathrm{q} / 11}$-protein coupled receptors from group I reduces cell proliferation in embryonic neural progenitors from the striatal anlage (Luk et al. 2003; Gandhi et al. 2008), but not from the embryonic cerebral cortex (Gandhi et al. 2008). Interestingly, however, hypoxia induces an mGluR5-mediated proliferation response also in the embryonic cerebral cortex progenitors (Zhao et al. 2012). Conversely, glutamatergic stimulation increases proliferation of NSCs in the embryonic cerebral cortex VZ, whereas TAPs located in the embryonic SVZ are rather decreased in proliferation by glutamatergic stimulation (Haydar et al. 2000). Thus, the response characteristics to glutamate differ profoundly between NSCs and TAPs at embryonic stages. The response of adult NSCs large resembles that of embryonic cells but also shows some differences. The proliferation of early postnatal NSCs from the SGZ and SEZ is promoted by mGluR5 (Di Giorgi-Gerevini et al. 2005), whereas adult NSCs in SGZ seem no longer responsive (Xu et al. 2012). The difference in response of embryonic and adult NSCs to mGluR5 is likely not a consequence of mGluR5 expression as both neurogenic niches express the receptor (Di Giorgi-Gerevini et al. 2005; Gandhi et al. 2008; Nakamichi et al. 2008; Muth-Kohne et al. 2010b). This disparity may lie in different downstream signaling pathways, receptor interactions, or even a difference in the source and mode of delivery of glutamate.

In contrast to $\mathrm{G}_{\mathrm{q} / 11}$-protein-coupled mGluR5 receptors, group III (such as mGluR7) receptors (coupled to $\mathrm{G}_{\mathrm{i} / \mathrm{o}}$-proteins) reduce cell proliferation in embryonic cerebral cortex neural progenitors (Nakamichi et al. 2008). Unfortunately, nothing is known about the role of mGluR7 in adult neurogenesis despite the expression of the receptor in DG granule cells (Kinzie et al. 1995). However, blocking group II receptors (that are also $\mathrm{G}_{\mathrm{i} / \mathrm{o}}$-protein-coupled) are reported to reduce proliferation in the adult SGZ in vivo (Yoshimizu and Chaki 2004). As the antiproliferative actions of $\mathrm{G}_{\mathrm{i} / \mathrm{o}}$-proteincoupled glutamate receptors were tested in cells from the entire embryonic neocortex (Nakamichi et al. 2008), which includes both TAPs located in the SVZ and NSCs located in the VZ, the conclusive comparison between embryonic and adult NSCs with regard to these receptors requires further investigations.

The situation with ionotropic glutamate receptors is even less clear. This is influenced in part by limited knowledge on the receptor composition and actions in the adult NSCs and progenitors. In embryonic cerebral cortex progenitors, $\mathrm{GABA}_{\mathrm{A}}$ receptor expression precedes expression of glutamatergic receptors (Muth-Kohne et al.2010b). Calcium-permeable AMPA receptors containing a specific GluRA2 
M. Götz et al.

subunit (Whitney et al. 2008) are expressed before the onset of NMDA receptors in more differentiating conditions (LoTurco et al. 1991; Muth-Kohne et al. 2010a). In the adult SGZ, although proliferating cells express NMDAR1 and AMPA GluR2 subunits (Bekiari et al. 2015), aNSCs were originally reported as responding to GABA but not to glutamate stimulation (Tozuka et al. 2005). However, this apparent functional absence of responsiveness to glutamate may be because of the fact that receptor agonists were applied to the soma of aNSCs (Tozuka et al. 2005) and not to their tufted processes that was only recently reported to harbor AMPA/kainate functional receptors (Renzel et al. 2013). These receptors seem to be absent in aNSCs of the SEZ (Liu et al. 2006), which correlates with a reduction of the number of cells expressing NMDAR1, R2A, and R2B subunits from early postnatal age to adulthood (Fan et al. 2012). Fewer NBs respond to NMDA stimulation in the SEZ than in the RMS, where NMDA receptors regulate their survival (Platel et al.2010). The absence of ionotropic glutamate receptors in the adult SEZ and their functional presence in embryonic NSCs again underlines key differences between embryonic and adult neurogenesis.

Release of glutamate in the adult SGZ was originally suggested as a signal of increased neuronal excitability that promotes proliferation via NMDA receptors (Deisseroth et al. 2004). However, blocking NMDA receptors was also found to increase proliferation of embryonic progenitors in vitro (Hirasawa et al. 2003) as well as progenitors from the adult SGZ in vivo (Cameron et al. 1995; Nacher et al. 2001; Kitayama et al. 2003; Bursztajn et al. 2007). Such discrepancies may result from differences in the technical design of the studies because the length of the treatment with NMDA receptor agonists determines whether they act as proor antiproliferative agents (Joo et al. 2007). Thus, it is important to consider the effects of tonic versus phasic glutamate release as well as its origin. Although mossy cells provide phasic synaptic glutamate releases for newborn neurons in the adult SGZ that determine their maturation (Chancey et al. 2014), the actual gluta- mate source influencing proliferation in the adult SGZ is currently unknown. It may come from glutamatergic projections of neurons from the enthorhinal cortex to the molecular layer of the DG (Cameron et al. 1995). The mode of neurotransmitter release (tonic vs. phasic) brings us back to the initial concept of structural and cellular differences between embryonic and adult brains. Although the developing brain contains an interconnected network of radial glia/NSCs and synaptic connections between early-born neurons, it lacks, among other factors, astrocytes, oligodendrocytes, and NG2 glia with their neurotransmitter buffering capacity (Parpura and Verkhratsky 2012), and most neurotransmitters are likely to originate from neuronal synaptic release. Therefore, differences in the duration and cellular source of the neurotransmitter release may well explain differential effects on embryonic and adult NSCs. In addition, recently available transcriptome data (Pinto et al. 2008; Beckervordersandforth et al. 2010; Bracko et al. 2012; Codega et al. 2014) may further help define developmental changes in the expression of neurotransmitter receptor subtypes and their downstream effectors, which may mediate specific signaling pathways in embryonic versus adult NSCs.

\section{CONCLUDING REMARKS}

The aforementioned comparisons highlight an important overarching concept in understanding the similarities and differences of NSCs in development and adulthood. Foremost, growing evidence has revealed that adult NSCs are not just a leftover of progenitors that are not used during development. Rather, they are specified and set aside at early developmental stages under the control of additional (and in some sense more advanced) layers of regulations that are specifically designed to suit their needs. Such a need is, for example, long-term preservation of multipotency of adult NSCs. This is not required during development when NSCs can have high levels of neurogenic fate determinants during the first neurogenic phase with glial progenitors specified and amplifying at later stages. Conversely, adult NSCs must be ready 
for both glial and neuronal lineages depending on the respective acute needs, and they remain so over a long period throughout life. In fact, NSCs in the SEZ retain the capacity to produce both oligodendrocytes and astrocyes, as well as neurons, at the adult stage under intact and injured conditions (Hack et al. 2004; Menn et al. 2006; Jablonska et al. 2010; Benner et al. 2013; Ortega et al. 2013; Rafalski et al. 2013; Sohn et al. 2015).

A further key difference is the regulation of embryonic and adult NSC proliferation. The embryonic NSCs have to generate a certain number of neuronal and glial progeny in a rather fixed number of cell division and with a preset magnitude of the output, that is, brain size. Conversely, adult NSCs generate specific subtypes of neurons that influence neuronal network properties in a delicate manner. Accordingly, activation of NSCs and the neuronal output is under control of many environmental factors increasing or decreasing adult neurogenesis (Urban and Guillemot 2014). To adapt newly generated neurons to the need of the neuronal network, synaptic and neurotransmitter activity plays a key role in this context, but has also striking similarities in development.

The other prevailing need of adult neurogenic NSCs is to overcome the gliogenic environment. This requires additional mechanisms for activation and maintenance of high levels of neurogenic fate determinants when embarking on neurogenesis. The full picture of the molecular logic underlying such additional regulations is not yet well understood. An emerging idea is that adult NSCs share the same core machinery with their embryonic counterparts, but possess additional modulatory mechanisms that change the mode of expression and action of individual components. It is tempting to speculate that such additional mechanisms allow stem cells to adapt to the antineurogenic environment unique to the adult brain, and to commence adult-specific tasks, such as the maintenance of undifferentiated cells over a prolonged period and altering the tempo and extent of neuronal production in response to various exogenous stimuli, such as neuronal activities, hormonal regulations, and injury (Na- kafuku and Grande 2013). The aforementioned Pax6-Brg1 interactions in continuous neurogenesis and the unique role of Gsx2 in injuryinduced neurogenesis are prime examples of such adult-specific regulatory mechanisms. Further studies on the molecular logic that governs the behavior of NSCs may provide important clues to further improve differentiation of NSCs or other cells into functional neurons even in the gliogenic environment of the adult CNS and hence further cell-based brain repair in the future.

\section{ACKNOWLEDGMENTS}

We are grateful to the Götz and Nakafuku laboratory members who contributed to the studies that were conducted in our laboratories and discussed in this review. Special thanks to Jovica Ninkovic for unpublished data, great discussions, and Figure 2 of this review. Our studies are supported by the German Research Foundation (DFG) via the SFB 870, the Synergy Excellence Cluster, the ICEMED Helmholtz Alliance and the European Research Commission (ERC) Grant ChroNeuroRepair: GA No. 340793 to M.G. and National Institutes of Health/National Institute of Neurological Disorders and Stroke (NIH/NINDS) Grant 2R01NS06989306 to M.N.

\section{REFERENCES}

Andang M, Hjerling-Leffler J, Moliner A, Lundgren TK, Castelo-Branco G, Nanou E, Pozas E, Bryja V, Halliez S, Nishimaru H, et al. 2008. Histone H2AX-dependent $\mathrm{GABA}_{\mathrm{A}}$ receptor regulation of stem cell proliferation. Nature 451: 460-464.

Andersen J, Urbán N, Achimastou A, Ito A, Simic M, Ullom K, Martynoga B, Lebel M, Göritz C, Frisén J, et al. 2014. A transcriptional mechanism integrating inputs from extracellular signals to activate hippocampal stem cells. Neuron 83: 1085-1097.

Anderson SA, Qiu M, Bulfone A, Eisenstat DD, Meneses J, Pedersen R, Rubenstein JL. 1997. Mutations of the homeobox genes $D l x-1$ and $D l x-2$ disrupt the striatal subventricular zone and differentiation of late born striatal neurons. Neuron 19: 27-37.

Arai Y, Pulvers JN, Haffner C, Schilling B, Nüsslein I, Calegari F, Huttner WB. 2011. Neural stem and progenitor cells shorten S-phase on commitment to neuron production. Nat Commun 2: 154. 
M. Götz et al.

Barnabé-Heider F, Göritz C, Sabelström H, Takebayashi H, Pfrieger FW, Meletis K, Frisén J. 2010. Origin of new glial cells in intact and injured adult spinal cord. Cell Stem Cell 7: $470-482$.

Batista-Brito R, Close J, Machold R, Fishell G. 2008. The distinct temporal origins of olfactory bulb interneuron subtypes. J Neurosci 28: 3966-3975.

Beckervordersandforth R, Tripathi P, Ninkovic J, Bayam E, Lepier A, Stempfhuber B, Kirchhoff F, Hirrlinger J, Haslinger A, Lie DC, et al. 2010. In vivo fate mapping and expression analysis reveals molecular hallmarks of prospectively isolated adult neural stem cells. Cell Stem Cell 7: 744-758.

Bekiari C, Giannakopoulou A, Siskos N, Grivas I, Tsingotjidou A, Michaloudi H, Papadopoulos GC. 2015. Neurogenesis in the septal and temporal part of the adult rat dentate gyrus. Hippocampus 25: 511-523.

Benner EJ, Luciano D, Jo R, Abdi K, Paez-Gonzalez P, Sheng H, Warner DS, Liu C, Eroglu C, Kuo CT. 2013. Protective astrogenesis from the SVZ niche after injury is controlled by Notch modulator Thbs4. Nature 497: 369-373.

Berger J, Berger S, Tuoc TC, D’Amelio M, Cecconi F, Gorski JA, Jones KR, Gruss P, Stoykova A. 2007. Conditional activation of Pax6 in the developing cortex of transgenic mice causes progenitor apoptosis. Development 134: 1311-1322.

Berninger B, Costa MR, Koch U, Schroeder T, Sutor B, Grothe B, Götz M. 2007. Functional properties of neurons derived from in vitro reprogrammed postnatal astroglia. J Neurosci 27: 8654-8664.

Bonaguidi MA, Peng CY, McGuire T, Falciglia G, Gobeske KT, Czeisler C, Kessler JA. 2008. Noggin expands neural stem cells in the adult hippocampus. J Neurosci 28: $9194-$ 9204.

Bonaguidi MA, Wheeler MA, Shapiro JS, Stadel RP, Sun GJ, Ming GL, Song H. 2011. In vivo clonal analysis reveals self-renewing and multipotent adult neural stem cell characteristics. Cell 145: 1142-1155.

Bowery NG, Bettler B, Froestl W, Gallagher JP, Marshall F, Raiteri M, Bonner TI, Enna SJ. 2002. International Union of Pharmacology. XXXIII. Mammalian $\gamma$-aminobutyric $\operatorname{acid}_{B}$ receptors: Structure and function. Pharmacol Rev 54: $247-264$.

Bracko O, Singer T, Aigner S, Knobloch M, Winner B, Ray J, Clemenson GD Jr, Suh H, Couillard-Despres S, Aigner L, et al. 2012. Gene expression profiling of neural stem cells and their neuronal progeny reveals IGF2 as a regulator of adult hippocampal neurogenesis. J Neurosci 32: 33763387.

Brill MS, Snapyan M, Wohlfrom H, Ninkovic J, Jawerka M, Mastick GS, Ashery-Padan R, Saghatelyan A, Berninger B, Götz M. 2008. A Dlx2- and Pax6-dependent transcriptional code for periglomerular neuron specification in the adult olfactory bulb. J Neurosci 28: 6439-6452.

Brill MS, Ninkovic J, Winpenny E, Hodge RD, Ozen I, Yang R, Lepier A, Gascón S, Erdelyi F, Szabo G, et al. 2009. Adult generation of glutamatergic olfactory bulb interneurons. Nat Neurosci 12: 1524-1533.

Buffo A, Vosko MR, Ertürk D, Hamann GF, Jucker M, Rowitch D, Götz M. 2005. Expression pattern of the transcription factor Olig2 in response to brain injuries: Im- plications for neuronal repair. Proc Natl Acad Sci 102: 18183-18188.

Bulfone A, Wang F, Hevner R, Anderson S, Cutforth T, Chen S, Meneses J, Pedersen R, Axel R, Rubenstein JL. 1998. An olfactory sensory map develops in the absence of normal projection neurons or GABAergic interneurons. Neuron 21: $1273-1282$.

Bursztajn S, Falls WA, Berman SA, Friedman MJ. 2007. Cell proliferation in the brains of NMDAR NR1 transgenic mice. Brain Res 1172: 10-20.

Calzolari F, Michel J, Baumgart EV, Theis F, Götz M, Ninkovic J. 2015. Fast clonal expansion and limited neura stem cell self-renewal in the adult subependymal zone. Nat Neurosci 18: 490-492.

Cameron HA, McEwen BS, Gould E. 1995. Regulation of adult neurogenesis by excitatory input and NMDA receptor activation in the dentate gyrus. J Neurosci 15: 46874692.

Cao QL, Howard RM, Dennison JB, Whittemore SR. 2002. Differentiation of engulfed neuronal-restricted precursor cells is inhibited in the traumatically injured spinal cord. Exp Neurol 177: 349-359.

Casarosa S, Fode C, Guillemot F. 1999. Mash1 regulates neurogenesis in the ventral telencephalon. Development 12n6: 525-534.

Chancey JH, Poulsen DJ, Wadiche JI, Overstreet-Wadiche L. 2014. Hilar mossy cells provide the first glutamatergic synapses to adult-born dentate granule cells. J Neurosci 34: 2349-2354.

Chapman H, Waclaw RR, Pei Z, Nakafuku M, Campbell K. 2013. The homeobox gene Gsx 2 controls the timing of oligodendroglial fate specification in mouse lateral ganglionic eminence progenitors. Development 140: 22892298.

Chen KC, Hsi E, Hu CY, Chou WW, Liang CL, Juo SH. 2012. MicroRNA-328 may influence myopia development by mediating the PAX6 gene. Invest Ophthalmol Vis Sci 53: 2732-2739.

Choe Y, Kozlova A, Graf D, Pleasure SJ. 2013. Bone morphogenic protein signaling is a major determinant of dentate development. J Neurosci 33: 6766-6775.

Clarke L, van der Kooy D. 2011. The adult mouse dentate gyrus contains populations of committed progenitor cells that are distinct from subependymal zone neural stem cells. Stem Cells 29: 1448-1458.

Codega P, Silva-Vargas V, Paul A, Maldonado-Soto AR, Deleo AM, Pastrana E, Doetsch F. 2014. Prospective identification and purification of quiescent adult neural stem cells from their in vivo niche. Neuron 82: 545-559.

Colak D, Mori T, Brill MS, Pfeifer A, Falk S, Deng C, Monteiro R, Mummery C, Sommer L, Götz M. 2008. Adult neurogenesis requires Smad4-mediated bone morphogenic protein signaling in stem cells. J Neurosci 28: 434-446.

Collingridge GL, Olsen RW, Peters J, Spedding M. 2009. A nomenclature for ligand-gated ion channels. Neuropharmacology 56: 2-5.

Corbin JG, Gaiano N, Machold RP, Langston A, Fishell G. 2000. The Gsh2 homeodomain gene controls multiple aspects of telencephalic development. Development 127: 5007-5020. 
Costa MR, Ortega F, Brill MS, Beckervordersandforth R, Petrone C, Schroeder T, Götz M, Berninger B. 2011. Continuous live imaging of adult neural stem cell division and lineage progression in vitro. Development 138: 10571068.

de Chevigny A, Coré N, Follert P, Gaudin M, Barbry P, Béclin C, Cremer H. 2012. miR-7a regulation of Pax6 controls spatial origin of forebrain dopaminergic neurons. Nat Neurosci 15: 1120-1126.

Dehay C, Kennedy H. 2007. Cell-cycle control and cortical development. Nat Rev Neurosci 8: 438-450.

Deisseroth K, Singla S, Toda H, Monje M, Palmer TD, Malenka RC. 2004. Excitation-neurogenesis coupling in adult neural stem/progenitor cells. Neuron 42: 535-552.

Di Giorgi-Gerevini V, Melchiorri D, Battaglia G, Ricci-Vitiani L, Ciceroni C, Busceti CL, Biagioni F, Iacovelli L, Canudas AM, Parati E, et al. 2005. Endogenous activation of metabotropic glutamate receptors supports the proliferation and survival of neural progenitor cells. Cell Death Differ 12: 1124-1133.

Dimou L, Götz M. 2014. Glial cells as progenitors and stem cells: New roles in the healthy and diseased brain. Physiol Rev 94: 709-737.

Encinas JM, Michurina TV, Peunova N, Park JH, Tordo J, Peterson DA, Fishell G, Koulakov A, Enikolopov G. 2011. Division-coupled astrocytic differentiation and age-related depletion of neural stem cells in the adult hippocampus. Cell Stem Cell 8: 566-579.

Enzmann GU, Benton RL, Woock JP, Howard RM, Tsoulfas P, Whittemore SR. 2005. Consequences of noggin expression by neural stem, glial, and neuronal precursor cells engrafted into the injured spinal cord. Exp Neurol 195: 293-304.

Fan H, Gao J, Wang W, Li X, Xu T, Yin X. 2012. Expression of NMDA receptor and its effect on cell proliferation in the subventricular zone of neonatal rat brain. Cell Biochem Biophys 62: 305-316.

Fernando RN, Eleuteri B, Abdelhady S, Nussenzweig A, Andäng M, Ernfors P. 2011. Cell cycle restriction by histone H2AX limits proliferation of adult neural stem cells. Proc Natl Acad Sci 108: 5837-5842.

Fuentealba LC, Obernier K, Alvarez-Buylla A. 2012. Adult neural stem cells bridge their niche. Cell Stem Cell 10: 698-708.

Furutachi S, Miya H, Watanabe T, Kawai H, Yamasaki N, Harada Y, Imayoshi I, Nelson M, Nakayama KI, Hirabayashi Y, et al. 2015. Slowly dividing neural progenitors are an embryonic origin of adult neural stem cells. $\mathrm{Nat} \mathrm{Neu-}$ rosci 18: 657-665.

Gabay L, Lowell S, Rubin LL, Anderson DJ. 2003. Deregulation of dorsoventral patterning by FGF confers trilineage differentiation capacity on CNS stem cells in vitro. Neuron 40: 485-499.

Gajera CR, Emich H, Lioubinski O, Christ A, Beckervordersandforth-Bonk R, Yoshikawa K, Bachmann S, Christensen EI, Götz M, Kempermann G, et al. 2010. LRP2 in ependymal cells regulates BMP signaling in the adult neurogenic niche. J Cell Sci 123: 1922-1930.

Gandhi R, Luk KC, Rymar VV, Sadikot AF. 2008. Group I mGluR5 metabotropic glutamate receptors regulate proliferation of neuronal progenitors in specific forebrain developmental domains. J Neurochem 104: 155-172.
Georgala PA, Carr CB, Price DJ. 2011. The role of Pax6 in forebrain development. Dev Neurobiol 71: 690-709.

Giachino C, Barz M, Tchorz JS, Tome M, Gassmann M, Bischofberger J, Bettler B, Taylor V. 2014. GABA suppresses neurogenesis in the adult hippocampus through $\mathrm{GABA}_{\mathrm{B}}$ receptors. Development 141: 83-90.

Götz M, Huttner WB. 2005. The cell biology of neurogenesis. Nat Rev Mol Cell Biol 6: 777-788.

Götz M, Sirko S, Beckers J, Irmler M. 2015. Reactive astrocytes as neural stem or progenitor cells: In vivo lineage, in vitro potential and genome-wide expression analysis. Glia doi: 10.1002/glia.22850.

Grande A, Sumiyoshi K, López-Juárez A, Howard J, Sakthivel B, Aronow B, Campbell K, Nakafuku M. 2013. Environmental impact on direct neuronal reprogramming in vivo in the adult brain. Nat Commun 4: 2373.

Grandel H, Brand M. 2013. Comparative aspects of adult neural stem cell activity in vertebrates. Dev Genes Evol 223: $131-147$.

Guérout N, Li X, Barnabé-Heider F. 2014. Cell fate control in the developing central nervous system. Exp Cell Res 321: 77-83.

Hack MA, Sugimori M, Lundberg C, Nakafuku M, Götz M. 2004. Regionalization and fate specification in neurospheres: The role of Olig2 and Pax6. Mol Cell Neurosci 25: 664-678.

Hack MA, Saghatelyan A, de Chevigny A, Pfeifer A, AsheryPadan R, Lledo PM, Götz M. 2005. Neuronal fate determinants of adult olfactory bulb neurogenesis. Nat Neurosci 8: $865-872$.

Hagan N, Ben-Zvi A. 2015. The molecular, cellular, and morphological components of blood-brain barrier development during embryogenesis. Semin Cell Dev Biol 38: $7-15$.

Haubst N, Berger J, Radjendirane V, Graw J, Favor J, Saunders GF, Stoykova A, Götz M. 2004. Molecular dissection of Pax6 function: The specific roles of the paired domain and homeodomain in brain development. Development 131: 6131-6140.

Haydar TF, Wang F, Schwartz ML, Rakic P. 2000. Differential modulation of proliferation in the neocortical ventricular and subventricular zones. J Neurosci 20: 5764-5774.

Heins N, Malatesta P, Cecconi F, Nakafuku M, Tucker KL, Hack MA, Chapouton P, Barde YA, Götz M. 2002. Glial cells generate neurons: The role of the transcription factor Pax6. Nat Neurosci 5: 308-315.

Herrera DG, Garcia-Verdugo JM, Alvarez-Buylla A. 1999. Adult-derived neural precursors transplanted into multiple regions in the adult brain. Ann Neurol 46: 867-877.

Hevner RF, Hodge RD, Daza RA, Englund C. 2006. Transcription factors in glutamatergic neurogenesis: Conserved programs in neocortex, cerebellum, and adult hippocampus. Neurosci Res 55: 223-233.

Hirasawa T, Wada H, Kohsaka S, Uchino S. 2003. Inhibition of NMDA receptors induces delayed neuronal maturation and sustained proliferation of progenitor cells during neocortical developmen. J Neurosci Res 74: 676-687.

Hofstetter CP, Holmström NA, Lilja JA, Schweinhardt P, Hao J, Spenger C, Wiesenfeld-Hallin Z, Kurpad SN, Frisén J, Olson L. 2005. Allodynia limits the usefulness 
M. Götz et al.

of intraspinal neural stem cell grafts; directed differentiation improves outcome. Nat Neurosci 8: 346-353.

Huettl R, Eckstein S, Stahl T, Petricca S, Ninkovic J, Götz M, Huber A. Functional dissection of the Pax6 paired domain: Roles in neural tube patterning and peripheral nervous system development. Dev Biol (in press).

Jablonska B, Aguirre A, Raymond M, Szabo G, Kitabatake Y, Sailor KA, Ming GL, Song H, Gallo V. 2010. Chordininduced lineage plasticity of adult SVZ neuroblasts after demyelination. Nat Neurosci 13: 541-550.

Jacobsen CT, Miller RH. 2003. Control of astrocyte migration in the developing cerebral cortex. Dev Neurosci 25: 207-216.

Jacquet BV, Salinas-Mondragon R, Liang H, Therit B, Buie JD, Dykstra M, Campbell K, Ostrowski LE, Brody SL, Ghashghaei HT. 2009. FoxJ1-dependent gene expression is required for differentiation of radial glia into ependymal cells and a subset of astrocytes in the postnatal brain. Development 136: 4021-4031.

Jessberger S, Toni N, Clemenson GD Jr, Ray J, Gage FH. 2008. Directed differentiation of hippocampal stem/progenitor cells in the adult brain. Nat Neurosci 11: 888-893.

Joo JY, Kim BW, Lee JS, Park JY, Kim S, Yun YJ, Lee SH, Lee SH, Rhim H, Son H. 2007. Activation of NMDA receptors increases proliferation and differentiation of hippocampal neural progenitor cells. J Cell Sci 120: 1358-1370.

Kaslin J, Ganz J, Brand M. 2008. Proliferation, neurogenesis and regeneration in the non-mammalian vertebrate brain. Philos Trans R Soc Lond B Biol Sci 363: 101-122.

Kelsch W, Sim S, Lois C. 2012. Increasing heterogeneity in the organization of synaptic inputs of mature olfactory bulb neurons generated in newborn rats. J Comp Neurol 520: $1327-1338$.

Kessaris N, Fogarty M, Iannarelli P, Grist M, Wegner M, Richardson WD. 2006. Competing waves of oligodendrocytes in the forebrain and postnatal elimination of an embryonic lineage. Nat Neurosci 9: 173-179.

Kim EJ, Leung CT, Reed RR, Johnson JE. 2007. In vivo analysis of Ascll defined progenitors reveals distinct developmental dynamics during adult neurogenesis and gliogenesis. J Neurosci 27: 12764-12774.

Kim EJ, Ables JL, Dickel LK, Eisch AJ, Johnson JE. 2011. Ascll (Mash1) defines cells with long-term neurogenic potential in subgranular and subventricular zones in adult mouse brain. PLoS ONE 6: e18472.

Kinzie JM, Saugstad JA, Westbrook GL, Segerson TP. 1995. Distribution of metabotropic glutamate receptor 7 messenger RNA in the developing and adult rat brain. $\mathrm{Neu}$ roscience 69: 167-176.

Kitayama T, Yoneyama M, Yoneda Y. 2003. Possible regulation by $\mathrm{N}$-methyl-D-aspartate receptors of proliferative progenitor cells expressed in adult mouse hippocampal dentate gyrus. J Neurochem 84: 767-780.

Kohwi M, Osumi N, Rubenstein JL, Alvarez-Buylla A. 2005. Pax6 is required for making specific subpopulations of granule and periglomerular neurons in the olfactory bulb. J Neurosci 25: 6997-7003.

Kriegstein A, Alvarez-Buylla A. 2009. The glial nature of embryonic and adult neural stem cells. Annu Rev Neurosci 32: $149-184$.
Kronenberg G, Gertz K, Cheung G, Buffo A, Kettenmann H, Götz M, Endres M. 2010. Modulation of fate determinants Olig2 and Pax6 in resident glia evokes spiking neuroblasts in a model of mild brain ischemia. Stroke 41: 2944-2949.

Lange C, Calegari F. 2010. Cdks and cyclins link $\mathrm{G}_{1}$ length and differentiation of embryonic, neural and hematopoietic stem cells. Cell Cycle 9: 1893-1900.

Lessard J, Wu JI, Ranish JA, Wan M, Winslow MM, Staahl BT, Wu H, Aebersold R, Graef IA, Crabtree GR. 2007. An essential switch in subunit composition of a chromatin remodeling complex during neural development. Neuron 55: $201-215$.

Li H, Tornberg J, Kaila K, Airaksinen MS, Rivera C. 2002. Patterns of cation-chloride cotransporter expression during embryonic rodent CNS development. Eur J Neurosci 16: $2358-2370$.

Liu X, Wang Q, Haydar TF, Bordey A. 2005. Nonsynaptic GABA signaling in postnatal subventricular zone controls proliferation of GFAP-expressing progenitors. Nat Neurosci 8: 1179-1187.

Liu X, Bolteus AJ, Balkin DM, Henschel O, Bordey A. 2006. GFAP-expressing cells in the postnatal subventricular zone display a unique glial phenotype intermediate between radial glia and astrocytes. Glia 54: 394-410.

Lledo PM, Merkle FT, Alvarez-Buylla A. 2008. Origin and function of olfactory bulb interneuron diversity. Trends Neurosci 31: 392-400.

Long JE, Garel S, Depew MJ, Tobet S, Rubenstein JL. 2003. DLX5 regulates development of peripheral and central components of the olfactory system. J Neurosci 23: $568-578$.

Long JE, Garel S, Alvarez-Dolado M, Yoshikawa K, Osumi N, Alvarez-Buylla A, Rubenstein JL. 2007. Dlx-dependent and -independent regulation of olfactory bulb interneuron differentiation. J Neurosci 27: 3230-3243.

Long JE, Swan C, Liang WS, Cobos I, Potter GB, Rubenstein JL. 2009. Dlx1\&2 and Mash1 transcription factors control striatal patterning and differentiation through parallel and overlapping pathways. J Comp Neurol 512: 556572.

López-Juárez A, Howard J, Ullom K, Howard L, Grande A, Pardo A, Waclaw R, Sun YY, Yang D, Kuan CY, et al. 2013. Gsx2 controls region-specific activation of neural stem cells and injury-induced neurogenesis in the adult subventricular zone. Genes Dev 27: 1272-1287.

LoTurco JJ, Blanton MG, Kriegstein AR. 1991. Initial expression and endogenous activation of NMDA channels in early neocortical development. J Neurosci 11: 792-799.

LoTurco JJ, Owens DF, Heath MJ, Davis MB, Kriegstein AR. 1995. GABA and glutamate depolarize cortical progenitor cells and inhibit DNA synthesis. Neuron 15: $1287-$ 1298.

Lugert S, Vogt M, Tchorz JS, Müller M, Giachino C, Taylor V. 2012. Homeostatic neurogenesis in the adult hippocampus does not involve amplification of Ascll(high) intermediate progenitors. Nat Commun 3: 670.

Luhmann HJ, Kirischuk S, Sinning A, Kilb W. 2014. Early GABAergic circuitry in the cerebral cortex. Curr Opin Neurobiol 26: 72-78. 
Luhmann HJ, Fukuda A, Kilb W. 2015. Control of cortical neuronal migration by glutamate and GABA. Front Cell Neurosci 9: 4.

Luk KC, Kennedy TE, Sadikot AF. 2003. Glutamate promotes proliferation of striatal neuronal progenitors by an NMDA receptor-mediated mechanism. J Neurosci 23: $2239-2250$.

Maekawa M, Takashima N, Arai Y, Nomura T, Inokuchi K, Yuasa S, Osumi N. 2005. Pax6 is required for production and maintenance of progenitor cells in postnatal hippocampal neurogenesis. Genes Cells 10: 1001-1014.

Matsumoto S, Banine F, Struve J, Xing R, Adams C, Liu Y, Metzger D, Chambon P, Rao MS, Sherman LS. 2006. Brgl is required for murine neural stem cell maintenance and gliogenesis. Dev Biol 289: 372-383.

Melchiorri D, Cappuccio I, Ciceroni C, Spinsanti P, Mosillo P, Sarichelou I, Sale P, Nicoletti F. 2007. Metabotropic glutamate receptors in stem/progenitor cells. Neuropharmacology 53: 473-480.

Menn B, Garcia-Verdugo JM, Yaschine C, Gonzalez-Perez O, Rowitch D, Alvarez-Buylla A. 2006. Origin of oligodendrocytes in the subventricular zone of the adult brain. $J$ Neurosci 26: 7907-7918.

Merkle FT, Mirzadeh Z, Alvarez-Buylla A. 2007. Mosaic organization of neural stem cells in the adult brain. Science 317: 381-384.

Merkle FT, Fuentealba LC, Sanders TA, Magno L, Kessaris N, Alvarez-Buylla A. 2014. Adult neural stem cells in distinct microdomains generate previously unknown interneuron types. Nat Neurosci 17: 207-214.

Miller FD, Gauthier AS. 2007. Timing is everything: Making neurons versus glia in the developing cortex. Neuron 54: $357-369$.

Mira H, Andreu Z, Suh H, Lie DC, Jessberger S, Consiglio A, San Emeterio J, Hortigüela R, Marqués-Torrejón MA, Nakashima K, et al. 2010. Signaling through BMPR-IA regulates quiescence and long-term activity of neural stem cells in the adult hippocampus. Cell Stem Cell 7: $78-89$.

Mirzadeh Z, Merkle FT, Soriano-Navarro M, Garcia-Verdugo JM, Alvarez-Buylla A. 2008. Neural stem cells confer unique pinwheel architecture to the ventricular surface in neurogenic regions of the adult brain. Cell Stem Cell 3: 265-278.

Morshead CM, Reynolds BA, Craig CG, McBurney MW, Staines WA, Morassutti D, Weiss S, van der Kooy D. 1994. Neural stem cells in the adult mammalian forebrain: A relatively quiescent subpopulation of subependymal cells. Neuron 13: 1071-1082.

Muth-Kohne E, Pachernegg S, Karus M, Faissner A, Hollmann M. 2010a. Expression of NMDA receptors and $\mathrm{Ca}^{2+}$-impermeable AMPA receptors requires neuronal differentiation and allows discrimination between two different types of neural stem cells. Cell Physiol Biochem 26: $935-946$.

Muth-Kohne E, Terhag J, Pahl S, Werner M, Joshi I, Hollmann M. 2010b. Functional excitatory $\mathrm{GABA}_{\mathrm{A}}$ receptors precede ionotropic glutamate receptors in radial glia-like neural stem cells. Mol Cell Neurosci 43: 209-221.

Nacher J, Rosell DR, Alonso-Llosa G, McEwen BS. 2001. NMDA receptor antagonist treatment induces a long lasting increase in the number of proliferating cells,
PSA-NCAM-immunoreactive granule neurons and radial glia in the adult rat dentate gyrus. Eur J Neurosci 13: 512-520.

Nacher J, Varea E, Blasco-Ibañez JM, Castillo-Gomez E, Crespo C, Martinez-Guijarro FJ, McEwen BS. 2005. Expression of the transcription factor Pax 6 in the adult rat dentate gyrus. J Neurosci Res 81: 753-761.

Nakafuku M, Grande A. 2013. Neurogenesis in the damaged mammalian brain. In Patterning and cell type specification in the developing CNS and PNS-Comprehensive developmental neuroscience, 1st ed. (ed. Rubenstein J, Rakic P). Academic, Amsterdam.

Nakamichi N, Yoshida K, Ishioka Y, Makanga JO, Fukui M, Yoneyama M, Kitayama T, Nakamura N, Taniura H, Yoneda Y. 2008. Group III metabotropic glutamate receptor activation suppresses self-replication of undifferentiated neocortical progenitor cells. J Neurochem 105: $1996-$ 2012.

Nakamichi N, Takarada T, Yoneda Y. 2009. Neurogenesis mediated by $\gamma$-aminobutyric acid and glutamate signaling. J Pharmacol Sci 110: 133-149.

Ninkovic J, Mori T, Götz M. 2007. Distinct modes of neuron addition in adult mouse neurogenesis. $J$ Neurosci 27 : 10906-10911.

Ninkovic J, Steiner-Mezzadri A, Jawerka M, Akinci U, Masserdotti G, Petricca S, Fischer J, von Holst A, Beckers J, Lie CD, et al. 2013. The BAF complex interacts with Pax6 in adult neural progenitors to establish a neurogenic crossregulatory transcriptional network. Cell Stem Cell 13: 404-408.

Ohori Y, Yamamoto S, Nagao M, Sugimori M, Yamamoto N, Nakamura K, Nakafuku M. 2006. Growth factor treatment and genetic manipulation stimulate neurogenesis and oligodendrogenesis by endogenous neural progenitors in the injured adult spinal cord. J Neurosci 26: 11948-11960.

Olsen RW, Sieghart W. 2008. International Union of Pharmacology. LXX. Subtypes of $\gamma$-aminobutyric acid $_{\mathrm{A}}$ receptors: Classification on the basis of subunit composition, pharmacology, and function. Update. Pharmacol Rev 60: 243-260.

Ortega F, Gascón S, Masserdotti G, Deshpande A, Simon C, Fischer J, Dimou L, Chichung Lie D, Schroeder T, Berninger B. 2013. Oligodendrogliogenic and neurogenic adult subependymal zone neural stem cells constitute distinct lineages and exhibit differential responsiveness to Wnt signalling. Nat Cell Biol 15: 602-613.

Osumi N, Shinohara H, Numayama-Tsuruta K, Maekawa M. 2008. Concise review: Pax6 transcription factor contributes to both embryonic and adult neurogenesis as a multifunctional regulator. Stem Cells 26: 1663-1672.

Paez-Gonzalez P, Abdi K, Luciano D, Liu Y, Soriano-Navarro M, Rawlins E, Bennett V, Garcia-Verdugo JM, Kuo CT. 2011. Ank3-dependent SVZ niche assembly is required for the continued production of new neurons. Neuron 71 : $61-75$.

Parpura V, Verkhratsky A. 2012. Astrocytes revisited: Concise historic outlook on glutamate homeostasis and signaling. Croat Med J 53: 518-528.

Parras CM, Galli R, Britz O, Soares S, Galichet C, Battiste J, Johnson JE, Nakafuku M, Vescovi A, Guillemot F. 2004. 
M. Götz et al.

Mash1 specifies neurons and oligodendrocytes in the postnatal brain. EMBO J 23: 4495-4505.

Pei Z, Wang B, Chen G, Nagao M, Nakafuku M, Campbell K. 2011. Homeobox genes Gsx1 and Gsx2 differentially regulate telencephalic progenitor maturation. Proc Natl Acad Sci 108: 1675-1680.

Pilz GA, Shitamukai A, Reillo I, Pacary E, Schwausch J, Stahl R, Ninkovic J, Snippert HJ, Clevers H, Godinho L, et al. 2013. Amplification of progenitors in the mammalian telencephalon includes a new radial glial cell type. Nat Commun 4: 2125.

Pinto L, Mader MT, Irmler M, Gentilini M, Santoni F, Drechsel D, Blum R, Stahl R, Bulfone A, Malatesta P, et al. 2008. Prospective isolation of functionally distinct radial glial subtypes-lineage and transcriptome analysis. Mol Cell Neurosci 38: 15-42.

Platel JC, Dave KA, Gordon V, Lacar B, Rubio ME, Bordey A. 2010. NMDA receptors activated by subventricular zone astrocytic glutamate are critical for neuroblast survival prior to entering a synaptic network. Neuron 65: 859872.

Qian X, Davis AA, Goderie SK, Temple S. 1997. FGF2 concentration regulates the generation of neurons and glia from multipotent cortical stem cells. Neuron 18: 81-93.

Qian X, Shen Q, Goderie SK, He W, Capela A, Davis AA, Temple S. 2000. Timing of CNS cell generation: A programmed sequence of neuron and glial cell production from isolated murine cortical stem cells. Neuron 28: 6980.

Qiu M, Bulfone A, Martinez S, Meneses JJ, Shimamura K, Pedersen RA, Rubenstein JL. 1995. Null mutation of $D l x-$ 2 results in abnormal morphogenesis of proximal first and second branchial arch derivatives and abnormal differentiation in the forebrain. Genes Dev 9: 2523-2538.

Rafalski VA, Ho PP, Brett JO, Ucar D, Dugas JC, Pollina EA, Chow LM, Ibrahim A, Baker SJ, Barres BA, et al. 2013. Expansion of oligodendrocyte progenitor cells following SIRT1 inactivation in the adult brain. Nat Cell Biol 15: 614-624.

Renzel R, Sadek AR, Chang CH, Gray WP, Seifert G, Steinhäuser C. 2013. Polarized distribution of AMPA, but not $\mathrm{GABA}_{\mathrm{A}}$, receptors in radial glia-like cells of the adult dentate gyrus. Glia 61: 1146-1154.

Rowitch DH, Kriegstein AR. 2010. Developmental genetics of vertebrate glial-cell specification. Nature 468: $214-$ 222.

Roybon L, Deierborg T, Brundin P, Li JY. 2009. Involvement of Ngn2, Tbr and NeuroD proteins during postnatal olfactory bulb neurogenesis. Eur J Neurosci 29: 232-243.

Seaberg RM, van der Kooy D. 2002. Adult rodent neurogenic regions: The ventricular subependyma contains neura stem cells, but the dentate gyrus contains restricted progenitors. J Neurosci 22: 1784-1793.

Shen Q, Wang Y, Dimos JT, Fasano CA, Phoenix TN, Lemischka IR, Ivanova NB, Stifani S, Morrisey EE, Temple S. 2006. The timing of cortical neurogenesis is encoded within lineages of individual progenitor cells. Nat Neurosci 9: 743-751.

Shibata M, Nakao H, Kiyonari H, Abe T, Aizawa S. 2011. MicroRNA-9 regulates neurogenesis in mouse telencephalon by targeting multiple transcription factors. J Neurosci 31: 3407-3422.
Shihabuddin LS, Ray J, Gage FH. 1997. FGF-2 is sufficient to isolate progenitors found in the adult mammalian spinal cord. Exp Neurol 148: 577-586.

Shihabuddin LS, Horner PJ, Ray J, Gage FH. 2000. Adult spinal cord stem cells generate neurons after transplantation in the adult dentate gyrus. J Neurosci 20: $8727-$ 8735.

Sohn J, Orosco L, Guo F, Chung SH, Bannerman P, Mills Ko E, Zarbalis K, Deng W, Pleasure D. 2015. The subventricular zone continues to generate corpus collosum and rostral migratory stream astroglia in normal adult mice. J Neurosci 35: 3756-3763.

Song J, Zhong C, Bonaguidi MA, Sun GJ, Hsu D, Gu Y, Meletis K, Huang ZJ, Ge S, Enikolopov G, et al. 2012. Neuronal circuitry mechanism regulating adult quiescent neural stem-cell fate decision. Nature 489: 150-154.

Spassky N, Merkle FT, Flames N, Tramontin AD, GarcíaVerdugo JM, Alvarez-Buylla A. 2005. Adult ependymal cells are postmitotic and are derived from radial glial cells during embryogenesis. J Neurosci 25: 10-8.

Stenman J, Toresson H, Campbell K. 2003. Identification of two distinct progenitor populations in the lateral ganglionic eminence: Implications for striatal and olfactory bulb neurogenesis. J Neurosci 23: 167-174.

Sugimori M, Nagao M, Bertrand N, Parras CM, Guillemot F, Nakafuku M. 2007. Combinatorial actions of patterning and HLH transcription factors in the spatiotemporal control of neurogenesis and gliogenesis in the developing spinal cord. Development 134: 1617-1629.

Taverna E, Götz M, Huttner WB. 2014. The cell biology of neurogenesis: Toward an understanding of the development and evolution of the neocortex. Annu Rev Cell Dev Biol 30: 465-502.

Toresson H, Campbell K. 2001. A role for Gsh1 in the developing striatum and olfactory bulb of Gsh2 mutant mice. Development 128: 4769-4780.

Toresson H, Potter SS, Campbell K. 2000. Genetic control of dorsal-ventral identity in the telencephalon: Opposing roles for Pax6 and Gsh2. Development 127: 4361-4371.

Torii M, Matsuzaki F, Osumi N, Kaibuchi K, Nakamura S, Casarosa S, Guillemot F, Nakafuku M. 1999. Transcription factors Mash-1 and Prox-1 delineate early steps in differentiation of neural stem cells in the developing central nervous system. Development 126: 443-456.

Torper O, Pfisterer U, Wolf DA, Pereira M, Lau S, Jakobsson J, Björklund A, Grealish S, Parmar M. 2013. Generation of induced neurons via direct conversion in vivo. Proc Natl Acad Sci 110: 7038-7043.

Tozuka Y, Fukuda S, Namba T, Seki T, Hisatsune T. 2005. GABAergic excitation promotes neuronal differentiation in adult hippocampal progenitor cells. Neuron 47: 803815.

Traynelis SF, Wollmuth LP, McBain CJ, Menniti FS, Vance KM, Ogden KK, Hansen KB, Yuan H, Myers SJ, Dingledine R. 2010. Glutamate receptor ion channels: Structure, regulation, and function. Pharmacol Rev 62: 405-496.

Tuoc TC, Stoykova A. 2008. Trim11 modulates the function of neurogenic transcription factor Pax6 through ubiquitin-proteosome system. Genes Dev 22: 1972-1986. 
Urban N, Guillemot F. 2014. Neurogenesis in the embryonic and adult brain: Same factors, different roles. Front Cell Neurosci 8: 396.

Waclaw RR, Allen ZJ II, Bell SM, Erdélyi F, Szabó G, Potter SS, Campbell K. 2006. The zinc finger transcription factor $\mathrm{Sp} 8$ regulates the generation and diversity of olfactory bulbinterneurons. Neuron 49: 503-516.

Waclaw RR, Wang B, Pei Z, Ehrman LA, Campbell K. 2009. Distinct temporal requirements for the homeobox gene Gsx2 in specifying striatal and olfactory bulb neuronal fates. Neuron 63: 451-465.

Waclaw RR, Ehrman LA, Pierani A, Campbell K. 2010. Developmental origin of the neuronal subtypes that comprise the amygdalar fear circuit in the mouse. J Neurosci 30: 6944-6953.

Walcher T, Xie Q, Sun J, Irmler M, Beckers J, Öztürk T, Niessing D, Stoykova A, Cvekl A, Ninkovic J, et al. 2013. Functional dissection of the paired domain of Pax6 reveals molecular mechanisms of coordinating neurogenesis and proliferation. Development 140: 11231136.

Wang DD, Krueger DD, Bordey A. 2003. GABA depolarizes neuronal progenitors of the postnatal subventricular zone via $\mathrm{GABA}_{\mathrm{A}}$ receptor activation. J Physiol 550: $785-$ 800.

Wang B, Waclaw RR, Allen ZJ 2nd, Guillemot F, Campbell K. 2009. Ascll is a required downstream effector of Gsx gene function in the embryonic mouse telencephalon. Neural Dev 4: 5 .

Weinandy F, Ninkovic J, Götz M. 2011. Restrictions in time and space-New insights into generation of specific neuronal subtypes in the adult mammalian brain. Eur J Neurosci 33: $1045-1054$

Weiss S, Dunne C, Hewson J, Wohl C, Wheatley M, Peterson AC, Reynolds BA. 1996. Multipotent CNS stem cells are present in the adult mammalian spinal cord and ventricular neuroaxis. J Neurosci 16: 7599-7609.

Whitney NP, Peng H, Erdmann NB, Tian C, Monaghan DT, Zheng JC. 2008. Calcium-permeable AMPA receptors containing Q/R-unedited GluR2 direct human neural progenitor cell differentiation to neurons. FASEB J 22: 2888-2900.

Willaime-Morawek S, Seaberg RM, Batista C, Labbé E, Attisano L, Gorski JA, Jones JR, Kam A, Morshead CM, van der Kooy D. 2006. Embryonic cortical neural stem cells migrate ventrally and persist as postnatal striatal stem cells. J Cell Biol 175: 159-168.
Xu X, Zhang J, Chen X, Liu J, Lu H, Yang P, Xiao X, Zhao L, Jiao Q, Zhao B, et al. 2012. The increased expression of metabotropic glutamate receptor 5 in subventricular zone neural progenitor cells and enhanced neurogenesis in a rat model of intracerebral hemorrhage. Neuroscience 202: $474-483$.

Yamamoto S, Nagao M, Sugimori M, Kosako H, Nakatomi H, Yamamoto N, Takebayashi H, Nabeshima Y, Kitamura T, Weinmaster G, et al. 2001a. Transcription factor expression and Notch-dependent regulation of neural progenitors in the adult rat spinal cord. J Neurosci 21: 9814 9923.

Yamamoto S, Yamamoto N, Kitamura T, Nakamura K, Nakafuku M. 2001b. Proliferation of parenchymal neural progenitors in response to injury in the adult rat spinal cord. Exp Neurol 172: 115-127.

Yang H, Lu P, McKay HM, Bernot T, Keirstead H, Steward O, Gage FH, Edgerton VR, Tuszynski MH. 2006. Endogenous neurogenesis replaces oligodendrocytes and astrocytes after primate spinal cord injury. J Neurosci 26: 2157-2166.

Yoshimizu T, Chaki S. 2004. Increased cell proliferation in the adult mouse hippocampus following chronic administration of group II metabotropic glutamate receptor antagonist, MGS0039. Biochem Biophys Res Commun 315: 493-496.

Young KM, Fogarty M, Kessaris N, Richardson WD. 2007. Subventricular zone stem cells are heterogeneous with respect to their embryonic origins and neurogenic fates in the olfactory bulb. J Neurosci 27: 8286-8296.

Young SZ, Platel JC, Nielsen JV, Jensen NA, Bordey A. 2010. $\mathrm{GABA}_{\mathrm{A}}$ increases calcium in subventricular zone astrocyte-like cells through L- and T-type voltage-gated calcium channels. Front Cell Neurosci 4: 8 .

Yun K, Potter S, Rubenstein JL. 2001. Gsh2 and Pax6 play complementary roles in dorsoventral patterning of the mammalian telencephalon. Development 128: $193-$ 205.

Yun K, Garel S, Fischman S, Rubenstein JL. 2003. Patterning of the lateral ganglionic eminence by the Gsh1 and Gsh2 homeobox genes regulates striatal and olfactory bulb histogenesis and the growth of axons through the basal ganglia. J Comp Neurol 461: 151-165.

Zhao L, Jiao Q, Chen X, Yang P, Zhao B, Zheng P, Liu Y. 2012. mGluR5 is involved in proliferation of rat neural progenitor cells exposed to hypoxia with activation of mitogenactivated protein kinase signaling pathway. J Neurosci Res 90: $447-460$. 


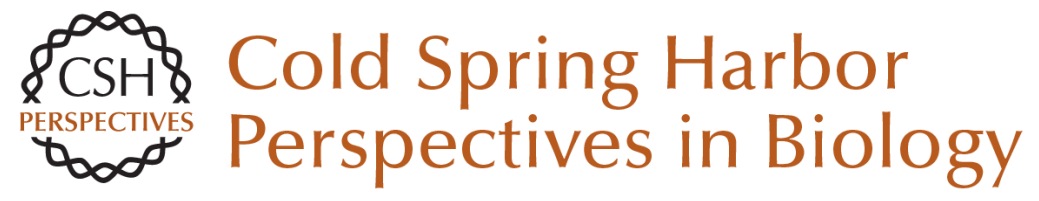

\title{
Neurogenesis in the Developing and Adult Brain--Similarities and Key Differences
}

\author{
Magdalena Götz, Masato Nakafuku and David Petrik
}

Cold Spring Harb Perspect Biol 2016; doi: 10.1101/cshperspect.a018853 originally published online May 27,2016

\section{Subject Collection Neurogenesis}

Adult Neurogenesis and Psychiatric Disorders Eunchai Kang, Zhexing Wen, Hongjun Song, et al.

Neuronal Circuitry Mechanisms Regulating Adult Mammalian Neurogenesis Juan Song, Reid H.J. Olsen, Jiaqi Sun, et al.

Neurogenesis in the Developing and Adult Brain --Similarities and Key Differences Magdalena Götz, Masato Nakafuku and David Petrik

Genetics and Epigenetics in Adult Neurogenesis Jenny Hsieh and Xinyu Zhao

The Adult Ventricular-Subventricular Zone (V-SVZ) and Olfactory Bulb (OB) Neurogenesis Daniel A. Lim and Arturo Alvarez-Buylla

Diversity of Neural Precursors in the Adult Mammalian Brain Michael A. Bonaguidi, Ryan P. Stadel, Daniel A. Berg, et al.

Detection and Phenotypic Characterization of Adult Neurogenesis

H. Georg Kuhn, Amelia J. Eisch, Kirsty Spalding, et al.

Maturation and Functional Integration of New Granule Cells into the Adult Hippocampus Nicolas Toni and Alejandro F. Schinder
Adult Olfactory Bulb Neurogenesis

Pierre-Marie Lledo and Matt Valley

Adult Neurogenesis in Fish Julia Ganz and Michael Brand

In Vitro Models for Neurogenesis Hassan Azari and Brent A. Reynolds Engineering of Adult Neurogenesis and
Gliogenesis

Benedikt Berninger and Sebastian Jessberger

Computational Modeling of Adult Neurogenesis James B. Aimone

Control of Adult Neurogenesis by Short-Range

Morphogenic-Signaling Molecules Youngshik Choe, Samuel J. Pleasure and Helena Mira

Adult Neurogenesis: An Evolutionary Perspective Gerd Kempermann

Epilepsy and Adult Neurogenesis

Sebastian Jessberger and Jack M. Parent

For additional articles in this collection, see http://cshperspectives.cshlp.org/cgi/collection/

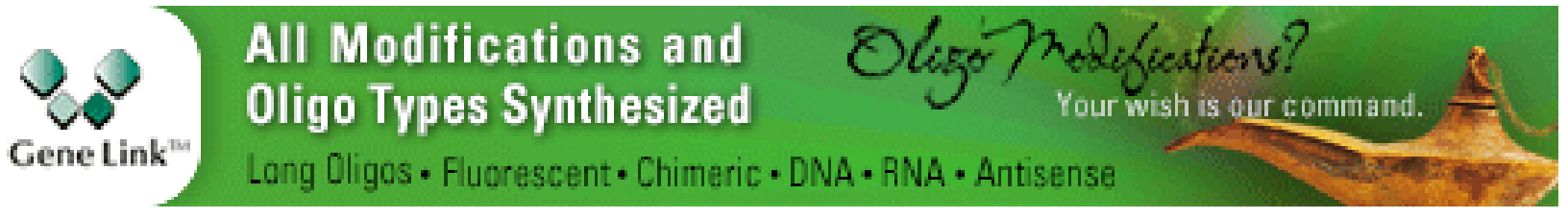


For additional articles in this collection, see http://cshperspectives.cshlp.org/cgi/collection/

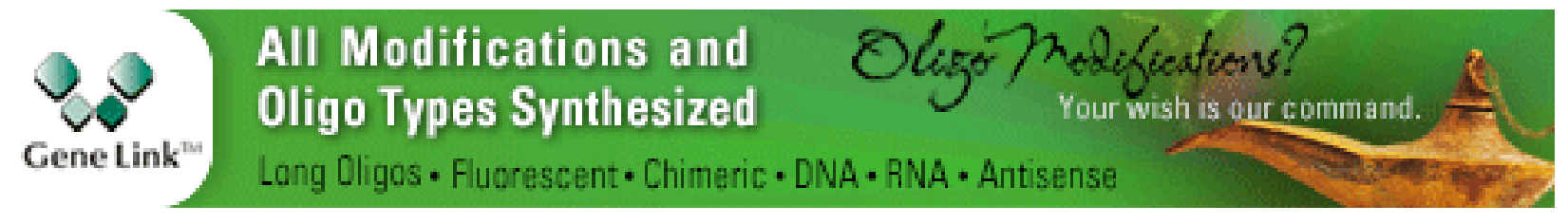

Copyright @ 2016 Cold Spring Harbor Laboratory Press; all rights reserved 